\title{
Chimeric antigen receptor T-cell therapy - assessment and management of toxicities
}

\author{
Sattva S. Neelapu', Sudhakar Tummala², Partow Kebriaei ${ }^{3}$, William Wierda4, \\ Cristina Gutierrez ${ }^{5}$, Frederick L. Locke ${ }^{6}$, Krishna V. Komanduri ${ }^{7}$, Yi Lin ${ }^{8}$, Nitin Jain $^{4}$, \\ Naval Daver ${ }^{4}$, Jason Westin ${ }^{1}$, Alison M. Gulbis ${ }^{9}$, Monica E. Loghin ${ }^{2}$, John F. de Groot ${ }^{2}$, \\ Sherry Adkins ${ }^{1}$, Suzanne E. Davis ${ }^{10}$, Katayoun Rezvani ${ }^{3}$, Patrick Hwu ${ }^{10}$, \\ Elizabeth J. Shpall ${ }^{3}$
}

Abstract | Immunotherapy using T cells genetically engineered to express a chimeric antigen receptor (CAR) is rapidly emerging as a promising new treatment for haematological and non-haematological malignancies. CAR-T-cell therapy can induce rapid and durable clinical responses, but is associated with unique acute toxicities, which can be severe or even fatal. Cytokine-release syndrome (CRS), the most commonly observed toxicity, can range in severity from low-grade constitutional symptoms to a high-grade syndrome associated with life-threatening multiorgan dysfunction; rarely, severe CRS can evolve into fulminant haemophagocytic lymphohistiocytosis (HLH). Neurotoxicity, termed CAR-T-cell-related encephalopathy syndrome (CRES), is the second most-common adverse event, and can occur concurrently with or after CRS. Intensive monitoring and prompt management of toxicities is essential to minimize the morbidity and mortality associated with this potentially curative therapeutic approach; however, algorithms for accurate and consistent grading and management of the toxicities are lacking. To address this unmet need, we formed a CAR-T-celltherapy-associated TOXicity (CARTOX) Working Group, comprising investigators from multiple institutions and medical disciplines who have experience in treating patients with various CAR-T-cell therapy products. Herein, we describe the multidisciplinary approach adopted at our institutions, and provide recommendations for monitoring, grading, and managing the acute toxicities that can occur in patients treated with CAR-T-cell therapy.

'Department of Lymphoma and Myeloma, the University of Texas MD Anderson Cancer Center,

1515 Holcombe Boulevard, Houston,

Texas 77030, USA

Correspondence to S.S.N sneelapu@mdanderson.org

doi:10.1038/nrclinonc. 2017.148 Published online 19 Sep 2017
Cellular immunotherapy with autologous or allogeneic $\mathrm{T}$ cells genetically engineered to express chimeric antigen receptors (CARs) or T-cell receptors (TCRs), in order to redirect their cytotoxic specificity towards tumour cells, is emerging as a promising new treatment modality for a broad range of cancers ${ }^{1,2}$. CARs consist of an extracellular domain that can bind specifically to a target molecule expressed on the surface of tumour cells, a transmembrane domain, and an intracellular domain that provides an activation signal to $\mathrm{T}$ cells when the extracellular domain is engaged with its target. The extracellular domain usually comprises the antigen-recognition regions of an antibody, in the form of a single-chain variable fragment ( $\mathrm{scFv}$ ); however, other molecules, such as ligands of cell-surface receptors, can also be used. The intracellular domain usually incorporates a region of the TCR $\mathrm{CD} 3 \zeta$ chain to provide 'signal $1^{\prime}$ and one or more domains from co-stimulatory receptors, such as CD28, OX40 (CD134), and/or 4-1BB (CD137), to provide 'signal 2' for T-cell activation. The adoptive T-cell-therapy approach that is most advanced in clinical development is the use of anti-CD19 CAR T cells for the treatment of $\mathrm{CD} 19^{+} \mathrm{B}$-cell malignancies, including acute and chronic B-cell leukaemias and B-cell nonHodgkin lymphomas (NHLs). The results of numerous phase I/II clinical trials conducted at single institutions indicate that this approach is typically associated with an overall response rate of $50-90 \%$ in patients with B-cell malignancies refractory to standard therapies ${ }^{3-20}$. More importantly, durable remissions have been noted, 


\section{Key points}

- Chimeric antigen receptor (CAR)-T-cell therapy is a promising approach for the treatment of refractory malignancies, but is associated with unique acute toxicities that need specialized monitoring and management

- Cytokine-release syndrome (CRS) and CAR-T-cell-related encephalopathy syndrome (CRES) are the most-common toxicities observed after CAR-T-cell therapy and, rarely, CRS can evolve into fulminant haemophagocytic lymphohistiocytosis (HLH)

- Intensive monitoring, accurate grading, and prompt management of toxicities with aggressive supportive care, anti-IL-6 therapy, and/or corticosteroids for severe cases could reduce the morbidity and mortality associated with CAR-T-cell therapy

- The guidelines proposed could also be used for grading and management of toxicities associated with other redirected-T-cell therapies, such as TCR-gene therapies and bispecific T-cell-engaging antibody (BiTE) therapies

suggesting that this therapeutic strategy can be curative $e^{3,11,20-22}$. The feasibility of central manufacturing of CAR-T-cell therapies and the safety of treatment with cryopreserved CAR-T-cell products has been demonstrated in multicentre clinical trials ${ }^{23-28}$, with efficacy comparable to that observed in single-institution trials, suggesting that these therapies might soon be broadly available. Several multicentre phase II clinical trials of anti-CD19 CAR T cells are ongoing, with the intent of obtaining regulatory approvals for the treatment of B-cell malignancies. Indeed, on 30th August 2017, the FDA approved the first anti-CD19 CAR-T-cell product, tisagenlecleucel, for the treatment of paediatric and young adult patients with relapsed and/or refractory B-cell precursor acute lymphoblastic leukaemia. In addition, novel targets, such as CD20, NY-ESO-1, and B-cell maturation antigen, are being explored with CAR-based and TCR-redirected cell therapies in preclinical studies and early phase clinical trials, in both haematological and non-haematological malignancies ${ }^{1,2,29}$.

As adoptive T-cell therapies become more widely used, recognition of their unique toxicities, which are distinct from those seen with traditional chemotherapies, monoclonal antibodies (mAbs), and small-molecule targeted therapies, is of the utmost importance. The two most commonly observed toxicities with CAR-T-cell therapies are cytokine-release syndrome (CRS), characterized by

\section{Author addresses}

${ }^{1}$ Department of Lymphoma and Myeloma, The University of Texas MD Anderson Cancer Center,

2Department of Neuro-Oncology, The University of Texas MD Anderson Cancer Center, ${ }^{3}$ Department of Stem Cell Transplantation and Cellular Therapy, The University of Texas MD Anderson Cancer Center,

${ }^{4}$ Department of Leukemia, The University of Texas MD Anderson Cancer Center, ${ }^{5}$ Department of Critical Care, The University of Texas MD Anderson Cancer Center, 1515 Holcombe Boulevard, Houston, Texas 77030, USA.

${ }^{6}$ Department of Blood and Marrow Transplantation and Cellular Immunotherapy, Moffitt Cancer Center, 12902 USF Magnolia Drive, Tampa, Florida 33613, USA. ${ }^{7}$ Adult Stem Cell Transplant Program, Sylvester Comprehensive Cancer Center, University of Miami, 1475 Northwest 12 th Avenue, Miami, Florida 33136, USA. ${ }^{8}$ Division of Hematology, Mayo Clinic, 200 First Street South West, Rochester, Minnesota 55905, USA.

${ }^{9}$ Division of Pharmacy, The University of Texas MD Anderson Cancer Center, ${ }^{10}$ Division of Cancer Medicine, The University of Texas MD Anderson Cancer Center, 1515 Holcombe Boulevard, Houston, Texas 77030, USA. high fever, hypotension, hypoxia, and/or multiorgan toxicity; and a CAR-T-cell-related encephalopathy syndrome (CRES), typically characterized by a toxic encephalopathic state with symptoms of confusion and delirium, and occasionally seizures and cerebral oedema ${ }^{30-33}$. Rare cases of fulminant haemophagocytic lymphohistiocytosis (HLH) (also known as macrophage-activation syndrome (MAS)), which is characterized by severe immune activation, lymphohistiocytic tissue infiltration, and immune-mediated multiorgan failure, have also been reported ${ }^{24,32,34,35}$. Such toxicities have also been observed in patients treated with other redirected-T-cell therapies, such as TCR-gene therapies and bispecific T-cell-engaging antibodies (BiTEs), and preclinically with CAR natural killer (NK) cells ${ }^{36-41}$. Indeed, both CRS and HLH/MAS have been observed in patients treated with blinatumomab, an anti-CD19/CD3 BiTE ${ }^{42}$. These toxicities are manageable in most patients, although some require monitoring and treatment in the intensive-care setting, and fatalities can occur, as emphasized by the clinical trial experiences reported to date (TABLE 1).

Accurate assessment and prompt management of toxicities can mitigate the adverse outcomes associated with these potentially curative immunotherapies. The overall goal of management is to maximize the benefit from the cellular therapy while minimizing the risk of life-threatening complications, particularly CRS and CRES. In order to develop a consistent approach to the monitoring, grading, and management of toxicities, we have formed a CAR-T-cell-therapy-associated TOXicity (CARTOX) Working Group, with representatives from multiple institutions and multiple medical disciplines, including haematological oncology, solid-tumour oncology, stem-cell transplantation, neurology, critical care, immunology, and pharmaceutical sciences. These investigators were selected based on their extensive experience in treating patients with various CAR-T-cell-therapy products and with other cellular therapies. Collectively, the authors have been involved in treating more than 100 adult patients with leukaemia or lymphoma ${ }^{3,4,6,16,17}$, using at least four different anti-CD19 CAR-T-cell platforms ${ }^{16,23,24,26-28}$ that were originally developed at academic institutions and subsequently licensed to commercial entities for further clinical development in multicentre trials. Over a period of 6 months, the CARTOX Working Group discussed the available evidence in the literature and their collective experience in treating these patients, and collectively developed recommendations and a practical guide for monitoring, grading, and management of CRS, CRES, and HLH/MAS in adult patients. These recommendations incorporate and expand on the criteria proposed previously by Lee et al. ${ }^{30}$ for the diagnosis and management of CRS arising after treatment with cellular therapies. Herein, we present and discuss the CARTOX management and treatment algorithms, with reference to a representative clinical case.

\section{Clinical case study}

A 34-year-old female presented with refractory diffuse large-B-cell lymphoma (DLBCL) that had progressed following standard rituximab, cyclophosphamide, 
Table 1 | Reported causes of death after CAR-T-cell therapies (excluding progressive disease)

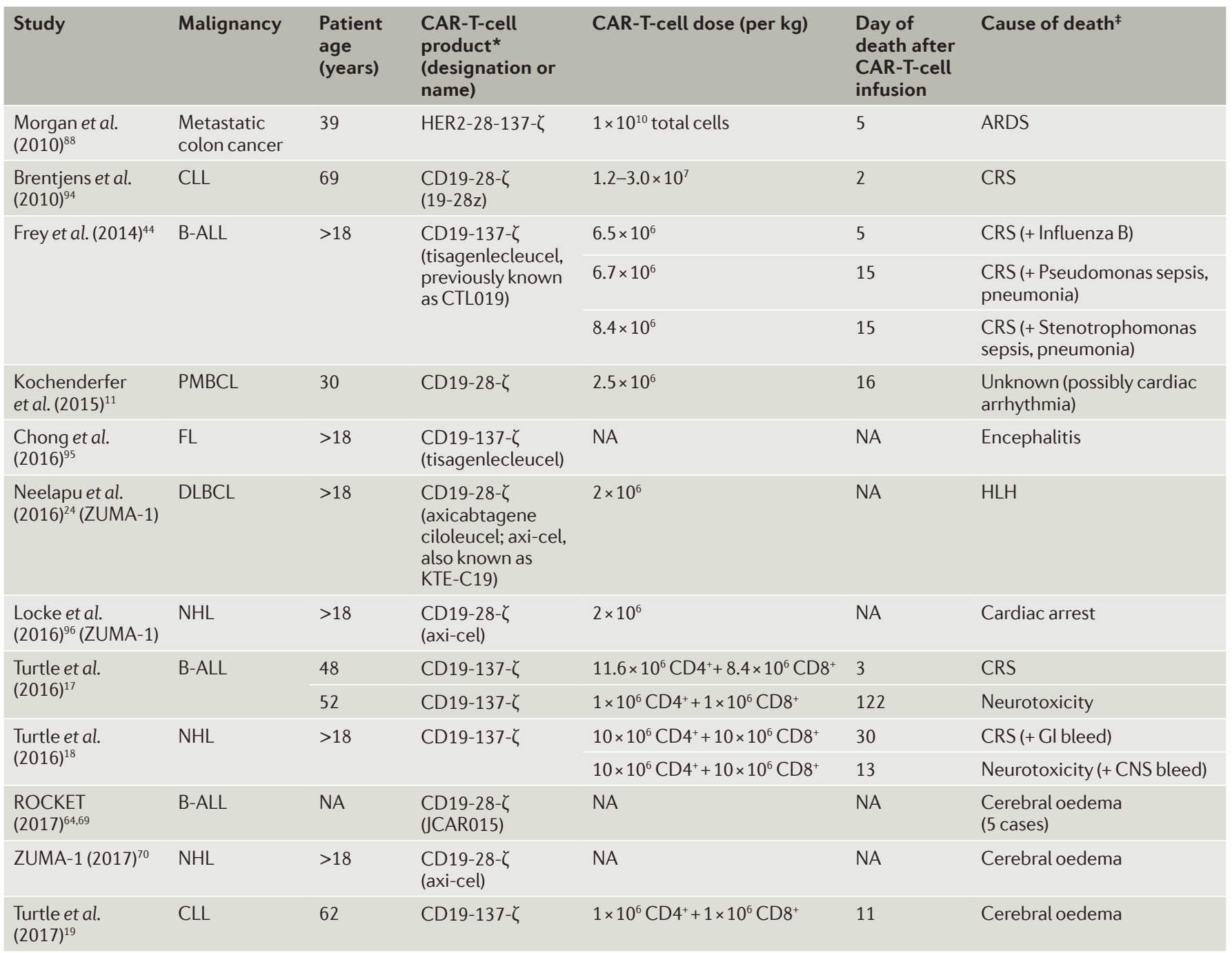

$\zeta$, T-cell receptor CD3 chain; 137, CD137 (4-1BB); 28, CD28; ARDS, acute respiratory distress syndrome; B-ALL, B-cell acute lymphoblastic leukaemia; CAR, chimeric antigen receptor; CLL, chronic lymphocytic leukaemia; CNS, central nervous system; CRS, cytokine-release syndrome; DLBCL, diffuse large-B-cell lymphoma;

FL, follicular lymphoma; GI, gastrointestinal; HLH, haemophagocytic lymphohistiocytosis; NA, not available; NHL, non-Hodgkin lymphoma; PMBCL, primary

mediastinal B-cell lymphoma. *In the format: target antigen/co-stimulatory domain/T-cell-receptor activation domain. ${ }^{\ddagger}$ Single case, unless otherwise noted.

doxorubicin, vincristine, and prednisone (R-CHOP) chemotherapy, and after subsequent salvage therapy consisting of rituximab, ifosfamide, carboplatin, and etoposide (R-ICE), followed by high-dose chemotherapy with autologous stem-cell transplantation (ASCT). After conditioning chemotherapy with cyclophosphamide and fludarabine, the woman was treated with autologous $\mathrm{T}$ cells transfected to express an anti-CD19-CAR construct incorporating $\mathrm{CD} 28$ and $\mathrm{CD} 3 \zeta$ signalling domain ${ }^{23}$. Within $24 \mathrm{~h}$ of the CAR-T-cell infusion, she developed high-grade fever of up to $39.5^{\circ} \mathrm{C}$, which was associated with tachycardia, fatigue, and decreased appetite that persisted for 6 days (FIG. 1a). The fever was classified as grade 1CRS according to the criteria proposed by Lee et al. ${ }^{30}$, and was managed with acetaminophen, ibuprofen, and a cooling blanket. She received empiric broad-spectrum antibiotics and growth-factor support for neutropenia - the work-up was negative for infection. She also developed hypotension with a systolic blood pressure of $84 \mathrm{mmHg}$ (classified as grade $2 \mathrm{CRS}^{30}$ ) on day 1 after CAR-T-cell infusion, and hypoxia on day 3 (grade $2 \mathrm{CRS}^{30}$ ), which were treated with an intravenous fluid bolus and supplemental nasal oxygen at $31 / \mathrm{min}$, respectively. In addition, on days 1 and 3 , she received intravenous tocilizumab $(8 \mathrm{mg} / \mathrm{kg})-$ a humanized anti-IL-6-receptor (IL-6R) mAb that blocks IL-6 binding to and signalling through its receptor - for the management of hypotension and hypoxia suspected to be caused by CRS, and responded promptly to this treatment. On day 5 , she developed handwriting impairment (dysgraphia) and subsequently became confused and disoriented (grade 2 confusion according to the Common Terminology Criteria for Adverse Events version 4.03 (CTCAE v4.03) ${ }^{43}$. Her dysgraphia was the earliest sign of neurotoxicity, and her contemporaneous mini-mental status examination (MMSE) score was 


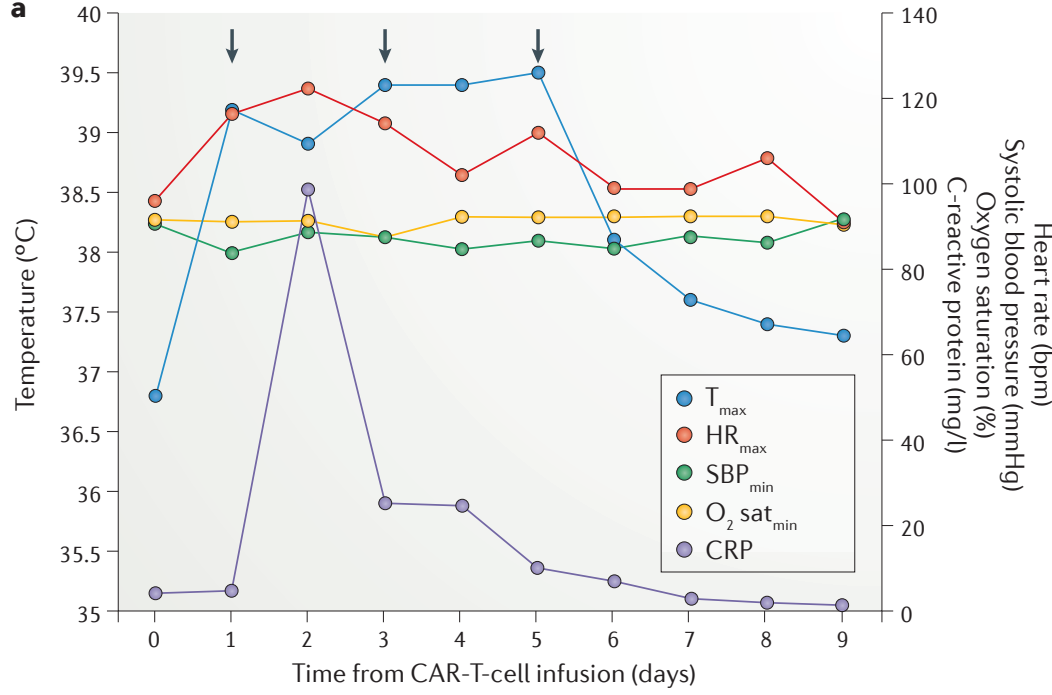

b

Day 4, MMSE 29/30

\& love Shawnee, KS.

Day 5, MMSE 27/30

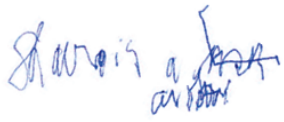

Day 6, MMSE 29/30
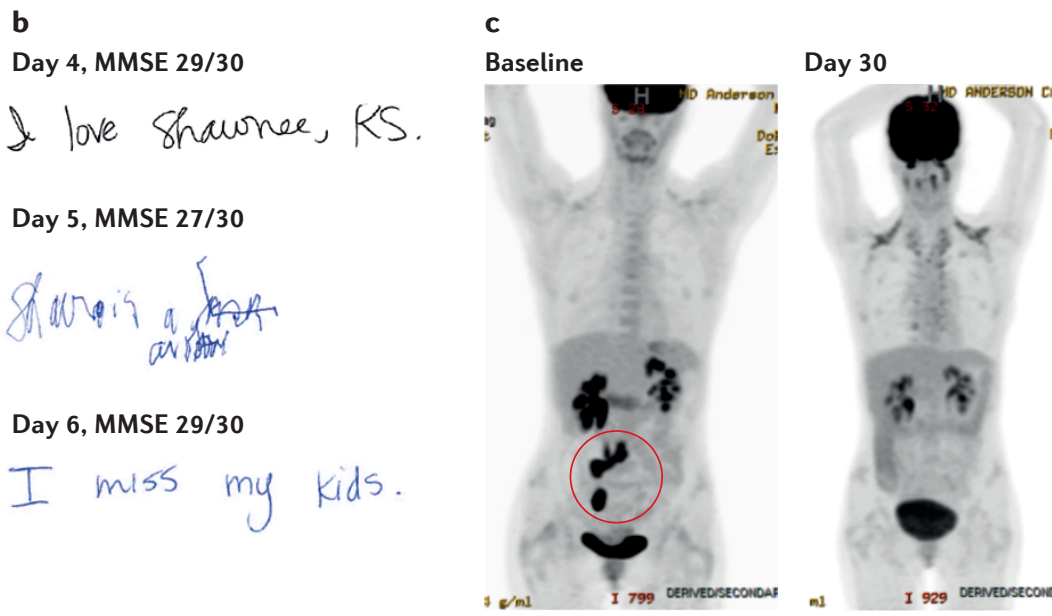

Figure 1 | Clinical case study. The findings of key clinical assessments are shown for a representative patient with cytokine-release syndrome and chimeric antigen receptor (CAR)-T-cell-related encephalopathy syndrome after anti-CD19 CAR-T-cell therapy for refractory diffuse large-B-cell lymphoma. a | The graph shows the patient's maximum temperature $\left(\mathrm{T}_{\max }\right)$, maximum heart rate $\left(\mathrm{HR}_{\max }\right)$, minimum systolic blood pressure $\left(\mathrm{SBP}_{\min }\right)$, minimum oxygen saturation $\left(\mathrm{O}_{2} \mathrm{sat}_{\min }\right)$, and serum $\mathrm{C}$-reactive protein (CRP) level recorded on each day after anti-CD19 CAR-T-cell therapy. The anti-IL-6 receptor antibody tocilizumab was administered on days 1,3 , and 5 (arrows) for the treatment of hypotension, hypoxia, and encephalopathy, respectively. $\mathbf{b} \mid$ Handwriting samples and mini mental status exam (MMSE) scores obtained on days 4, 5, and 6 after CAR-T-cell therapy; note how the patient's handwriting was markedly impaired on day 5 , despite only a small decrease in their MMSE score. $\mathbf{c} \mid 2$ 2-[ ${ }^{18}$ F]fluoro-2-deoxy-D-glucose PET images showing the retroperitoneal lymph nodes and ileocolic region harbouring lymphoma at baseline (highlighted in red circle; bottom left), and loss of tracer uptake indicative of induction of disease remission at 30 days after infusion of CAR T cells (bottom right).

only mildly decreased compared with that obtained at baseline (FIG. 1b). The neurotoxicity symptoms had resolved by $12 \mathrm{~h}$ after treatment with tocilizumab on day 5. Corticosteroids were not administered; tocilizumab was the first-choice treatment for the management of neurotoxicity because she had concurrent CRS symptoms with fever. The patient's serum C-reactive protein (CRP) level increased on day 2, a day after the onset of fever, and returned to baseline levels by the time the fever subsided (FIG. 1a). She was discharged on day 9.
Disease restaging on day 30 revealed that the patient was in complete remission (FIG. 1c), and she remains in remission 12 months later. Peak CAR-T-cell expansion in peripheral blood was observed within 2 weeks of cell infusion and circulating CAR $\mathrm{T}$ cells remained detectable at 12 months ${ }^{23}$. This case study does not illustrate the most-severe toxicities observed after CAR-T-cell therapy, although it does reflect the most commonly observed clinical scenario. The incidence and severity of toxicities reported varied in different multicentre trials. Whether this variation is because of differences in trial designs, patient populations, disease types, the toxicity grading systems used, or the CAR-T-cell platform is currently unclear. In the pivotal multicentre ZUMA-1 trial of axicabtagene ciloleucel (an anti-CD19-CD28-CD3 $\zeta$ CAR also known as axi-cel or KTE-C19) in 101 patients with refractory aggressive B-cell NHL, the rates of grade $\geq 3$ CRS and neurological toxicities were $13 \%$ and $28 \%$, respectively ${ }^{27}$. Conversely, in an interim analysis of the JULIET trial of tisagenlecleucel (an anti-CD194-1BB-CD3 C CAR previously known as CTL019) in 51 patients with relapsed or refractory DLBCL, these rates were $26 \%$ and $13 \%{ }^{26}$. Of note, the grading systems for CRS differed between these two trials.

\section{Grading and management of CRS}

Pathophysiology of CRS. CRS, the most-common toxicity of cellular immunotherapy, is triggered by the activation of $\mathrm{T}$ cells on engagement of their TCRs or CARs with cognate antigens expressed by tumour cells. The activated $\mathrm{T}$ cells release cytokines and chemokines (including IL-2, soluble IL-2Ra, IFN $\gamma$, IL-6, soluble IL-6R, and GM-CSF), as do bystander immune cells, such as monocytes and/or macrophages (which secrete IL-1RA, IL-10, IL-6, IL-8, CXCL10 (IP-10), CXCL9 (MIG), IFN $\alpha$, CCL3 (MIP-1 $\alpha$ ), CCL4 (MIP-1 $\beta$ ), and soluble IL-6R), dendritic cells, and others ${ }^{9,11,18,23,24,34}$. CRS typically manifests with constitutional symptoms, such as fever, malaise, anorexia, and myalgias, but can affect any organ system in the body, including cardiovascular, respiratory, integumentary, gastrointestinal, hepatic, renal, haematological, and nervous system $\mathrm{s}^{30-32}$ (TABLE 2). Patients at high risk of severe CRS include those with bulky disease, comorbidities, and those who develop early onset CRS within 3 days of cell infusion ${ }^{9,10,12}$; however, the correlation between the development of severe CRS and clinical parameters is imperfect, and identification of predictive biomarkers for severe toxicity is needed. Findings have demonstrated that high serum levels of IL-6, soluble gp130, IFN $\gamma$, IL-15, IL-8, and/or IL-10 either before or 1 day after CAR-T-cell infusion are associated with subsequent development of severe CRS ${ }^{18,34}$, but these results need to be confirmed in prospective studies; notably, the predictive values of these biomarkers seem to vary depending on the type of CAR-T-cell product used ${ }^{18,34}$.

General precautions and supportive care. The onset of CRS toxicity usually occurs within the first week after CAR-T-cell therapy, and typically peaks within 1-2 weeks of cell administration. In our experience, 
Table 2 | Grading of cytokine-release syndrome (CRS)

\begin{tabular}{|c|c|c|c|c|}
\hline Symptom or sign of CRS & CRS grade $1^{*}$ & CRS grade $2^{\ddagger}$ & CRS grade $3^{\ddagger}$ & CRS grade $4^{\ddagger}$ \\
\hline \multicolumn{5}{|l|}{ Vital signs } \\
\hline Temperature $\geq 38^{\circ} \mathrm{C}$ (fever) & Yes & Any & Any & Any \\
\hline Needing oxygen for $\mathrm{SaO}_{2}>90 \%$ (hypoxia) & No & $\mathrm{FiO}_{2}<40 \%$ & $\mathrm{FiO}_{2} \geq 40 \%$ & $\begin{array}{l}\text { Needing } \\
\text { ventilator support }\end{array}$ \\
\hline \multicolumn{5}{|l|}{ Organ toxicities" } \\
\hline $\begin{array}{l}\text { - Cardiac: tachycardia, arrhythmias, heart block, } \\
\text { low ejection fraction } \\
\text { - Respiratory: tachypnoea, pleural effusion, pulmonary oedema } \\
\text { - Gl: nausea, vomiting, diarrhoea } \\
\text { - Hepatic: increased serum ALT, AST, or bilirubin levels } \\
\text { - Renal: acute kidney injury (increased serum creatinine levels), } \\
\text { decreased urine output } \\
\text { - Dermatological: rash (less common) } \\
\text { - Coagulopathy: disseminated intravascular coagulation } \\
\text { (less common) }\end{array}$ & Grade 1 & Grade 2 & $\begin{array}{l}\text { Grade } 3 \text { or grade } 4 \\
\text { transaminitis }\end{array}$ & $\begin{array}{l}\text { Grade } 4 \\
\text { except grade } 4 \\
\text { transaminitis }\end{array}$ \\
\hline \multicolumn{5}{|c|}{ 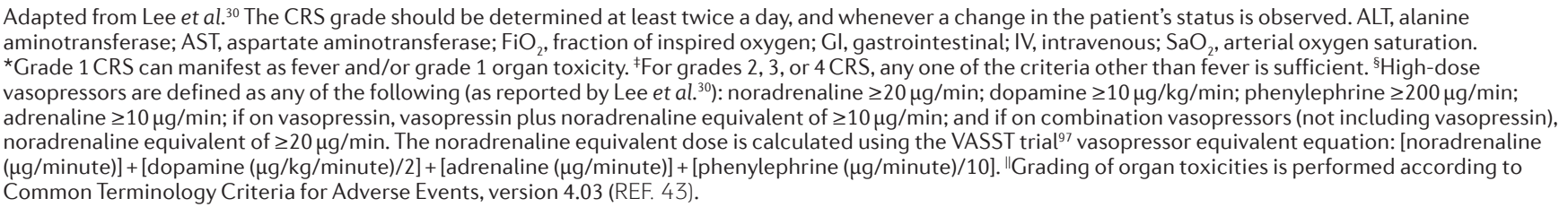 } \\
\hline
\end{tabular}

CRS tends to occur earlier in patients treated with

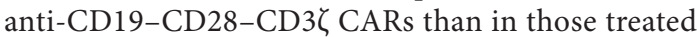
with anti-CD19-4-1BB-CD3 $\zeta$ CARs. Patient hospitalization with close monitoring is recommended for at least 7 days after CAR-T-cell infusion. Monitoring should include assessment of vital signs at least every $4 \mathrm{~h}$, and daily review of organ systems, physical exam, complete blood count with differential, complete metabolic profile, coagulation profiles, and measurement of serum CRP and ferritin levels (BOX 1). Laboratory tests, including blood counts and chemistry panel, might need to be performed more than once daily, especially for patients at high risk of severe CRS and/or CRES, or those with a high tumour burden, who are at risk of tumour lysis; for the latter group, precautions to avoid tumour lysis should be used, as per standard institutional guidelines. Owing to a high risk of arrhythmias, cardiac monitoring by telemetry is advised from the time of CAR-T-cell infusion until resolution of any emergent CRS symptoms. Additional investigations, such as chest radiography, electrocardiography, echocardiography, electroencephalography (EEG), and imaging studies, can be performed as needed, depending on the toxicities that arise. Daily fluid balance and bodyweights should be strictly monitored, and maintenance intravenous hydration is recommended for all patients with, or at risk of developing, CRS. Indeed, we recommend central venous access, preferably with a double or triple lumen catheter, before CAR-T-cell infusion, to facilitate the timely delivery of any medications needed to manage toxicities. Packed red blood cells and platelets can be transfused according to standard institutional guidelines. Corticosteroids should be avoided for the management of fever or for premedication before blood transfusions, in order to avoid limiting the effectiveness of CAR-T-cell therapy, but growth-factor support with filgrastim can be provided for neutropenia. Patients who develop fever should be assessed for infection using blood and urine cultures, chest radiography, and additional tests, such as cytomegalovirus PCR, respiratory viral screening, and CT of the chest, as indicated. Such tests should also be performed before initiation of CAR-T-cell therapy when infection is suspected. Therapy with CAR T cells should be delayed until infection has been controlled or ruled out; undiagnosed infections can have catastrophic consequences in patients with CRS, probably owing to exacerbation of systemic inflammation associated with the underlying infection, with deaths reported in clinical trials ${ }^{44}$ (TABLE 1). We recommend conditional orders for fever and hypotension should be put in place for all patients receiving CAR-T-cell infusion, in order that appropriately trained nursing staff can act quickly in the event of toxicities, thereby minimizing delays in intervention (BOX 1). These contingency orders should include empiric broad-spectrum antibiotic therapy, including Gram-negative bacterial coverage, because sepsis and CRS have overlapping symptoms and the absence of positive cultures cannot rule out pathogenic infection in immunocompromised patients with cancer.

IL-6 and IL-6R antagonists. Strong positive correlations of peak blood CAR-T-cell levels and serum IL-6 levels with the severity of CRS after CAR-T-cell therapy have been reported ${ }^{9,10,18,24}$. IL- 6 can signal by 
'cis-signalling', via direct binding to membrane-bound IL-6R and gp130 complexes, or by 'trans-signalling', whereby IL- 6 binds to soluble IL-6R and the resultant ligand-receptor complex interacts with membranebound gp130; both routes lead to activation of JAK/STAT pathway signalling ${ }^{45}$. The expression of membrane-bound IL-6R is restricted to haematopoietic cells, such as macrophages, neutrophils, and T cells, as well as hepatocytes, whereas membrane-bound gp130 is expressed abundantly on all cell types ${ }^{46}$. Thus, cis-signalling, which is activated at low levels of

\section{Box 1 | Supportive-care considerations for CAR-T-cell therapy}

\section{Before and during CAR-T-cell infusion}

- Baseline brain MRI to rule out any central nervous system (CNS) disease

- Central venous access, preferably with double or triple lumen catheter, for intravenous fluid and other infusions in case of toxicities

- Cardiac monitoring by telemetry starting on the day of CAR-T-cell infusion and continued until cytokine-release syndrome (CRS) resolves, in order to detect arrhythmias

- Tumour lysis precautions for patients with bulky tumours, as per standard institutional guidelines

- Seizure prophylaxis with levetiracetam at $750 \mathrm{mg}$ orally every $12 \mathrm{~h}$ for 30 days, starting on the day of infusion for CAR-T-cell therapies known to cause CAR-T-cell-related encephalopathy syndrome (CRES)

- Hospitalization recommended for at least 7 days after CAR-T-cell therapy

\section{Patient monitoring after CAR-T-cell infusion}

- Assess vital signs every $4 \mathrm{~h}$, close monitoring of oral and intravenous fluid input and urine output, and daily measurement of bodyweight

- Daily review of patient history and physical examination

- Daily blood counts, complete metabolic profiling, and coagulation profiling

- C-reactive protein and ferritin levels measured daily, starting on the day of infusion

- Assessment and grading of CRS should be done at least twice daily, and whenever the patient's status changes

- Assessment and grading of CRES using the CAR-T-cell-therapy-associated toxicity 10-point neurological assessment (CARTOX-10; TABLE 4) should be done at least every $8 \mathrm{~h}$

- Maintenance intravenous fluids with normal saline to ensure adequate hydration

\section{Notifications and contingency orders}

- The physician should be notified on detection of any of the following: systolic blood pressure (SBP) $>140 \mathrm{mmHg}$ or $<90 \mathrm{mmHg}$; heart rate $>120 \mathrm{bpm}$ or $<60 \mathrm{bpm}$, or arrhythmia; respiratory rate $>25$ breaths per min or $<12$ breaths per min; arterial oxygen saturation $<92 \%$ on room air; urine output $<1,500 \mathrm{ml}$ per day; upward trend in blood creatinine levels or the results of liver function tests; tremors or jerky movements in extremities; change in mental status (alertness, orientation, speech, ability to write a sentence, or CARTOX-10 score)

- For patients with a temperature $\geq 38.3^{\circ} \mathrm{C}$, order blood cultures (central and peripheral), urinalysis and urine cultures, portable chest radiography, and notify physician

- For patients with neutropenia and fever, start empiric broad-spectrum antibiotics

- Corticosteroids should not be administered unless approved by physician

- If patient develops CRES, withhold oral intake of food, fluids, and medicine, and notify physician

- Pro re nata (as needed) medications, acetaminophen (first choice) or ibuprofen (second choice, if not contraindicated), and cooling blanket for fever $\geq 38.3^{\circ} \mathrm{C}$; normal saline $500-1,000 \mathrm{ml}$ bolus for SBP $<90 \mathrm{mmHg}$, with one repeat if SBP remains $<90 \mathrm{mmHg}$ after first bolus

- Anti-IL-6 therapy with tocilizumab or siltuximab to be initiated only on physician order

CAR, chimeric antigen receptor.
IL-6, affects only a few cell types and mediates antiinflammatory effects. By contrast, trans-signalling predominates at higher levels of IL-6 (as occur in patients with CRS), can affect most cell types, and mediates proinflammatory effects ${ }^{46}$. Hence, tocilizumab or the chimeric anti-IL-6 mAb siltuximab have become the drugs of choice for the management of moderate-to-severe CRS $^{9,10,30,31,47}$. Tocilizumab is approved for the treatment of rheumatoid arthritis ${ }^{48}$, and siltuximab is approved for the management of multicentric Castleman disease $^{49}$; however, both agents have been used off-label for the management of CRS and induce rapid reversal of CRS symptoms in most patients ${ }^{9,10,30,31,34,50}$. In August 2017, together with the approval of tisagenlecleucel, the FDA also approved tocilizumab for the treatment of CRS occurring after CAR-T-cell therapy. To date, tocilizumab has been used more commonly than siltuximab for the management of CRS, and use of this agent does not seem to affect the efficacy of CAR-T-cell therapy, in terms of overall response rates, complete response rates, or the durability of responses , $10,12,23,24,27^{\text {. Nevertheless, }}$ whether the use of tocilizumab offers advantages over siltuximab treatment for the management of CRS remains unclear. Interestingly, IL-6 binds to IL-6R with an affinity $\left(\mathrm{K}_{\mathrm{d}}\right)$ of around $1 \mathrm{nM}$, whereas tocilizumab binds to IL-6R with a $\mathrm{K}_{\mathrm{d}}$ of $2.54 \mathrm{nM}$ (REFS 51,52) (Supplementary information S1 (table)); therefore, IL-6 might compete with tocilizumab for binding to IL-6R. By contrast, siltuximab inhibits IL- 6 with a $K_{d}$ of $\sim 1 \mathrm{pM}$ and, thus, IL-6R is unlikely to compete favourably with siltuximab for IL-6 binding. For this reason, siltuximab might be a more-effective treatment than tocilizumab for controlling CRS. In addition, serum IL-6 levels have been shown to increase after administration of tocilizumab, presumably by preventing the IL-6R-mediated uptake of IL-6 into peripheral tissues ${ }^{53}$; thus, a theoretical concern is that this effect might increase passive diffusion of IL-6 into the central nervous system (CNS) and thereby increase the risk of neurotoxicity. This scenario is unlikely to occur with siltuximab because it binds directly to IL-6. Prospective clinical studies are needed to directly compare the effectiveness of tocilizumab and siltuximab in the treatment of CRS.

Corticosteroids usage. Corticosteroids also suppress inflammatory responses and are, therefore, effective in the management of CRS, CRES, and HLH/MAS associated with cellular therapies ${ }^{30-32}$. However, because corticosteroids suppress T-cell function and/or induce T-cell apoptosis ${ }^{5-56}$, use of these drugs should be avoided for other indications (such as premedication for blood transfusions) after adoptive T-cell therapy. Of note, data from studies in allogeneic stem-cell transplant recipients have demonstrated that cytomegalovirus-specific T cells can persist despite corticosteroid therapy, but have impaired cytokine production ${ }^{57}$. In the setting of cellbased immunotherapy, these findings suggest that corticosteroids will impair the function, if not the persistence, of the infused tumour-directed T cells. Preliminary data from one clinical trial suggest, however, that corticosteroid use for the management of toxicities resulting 


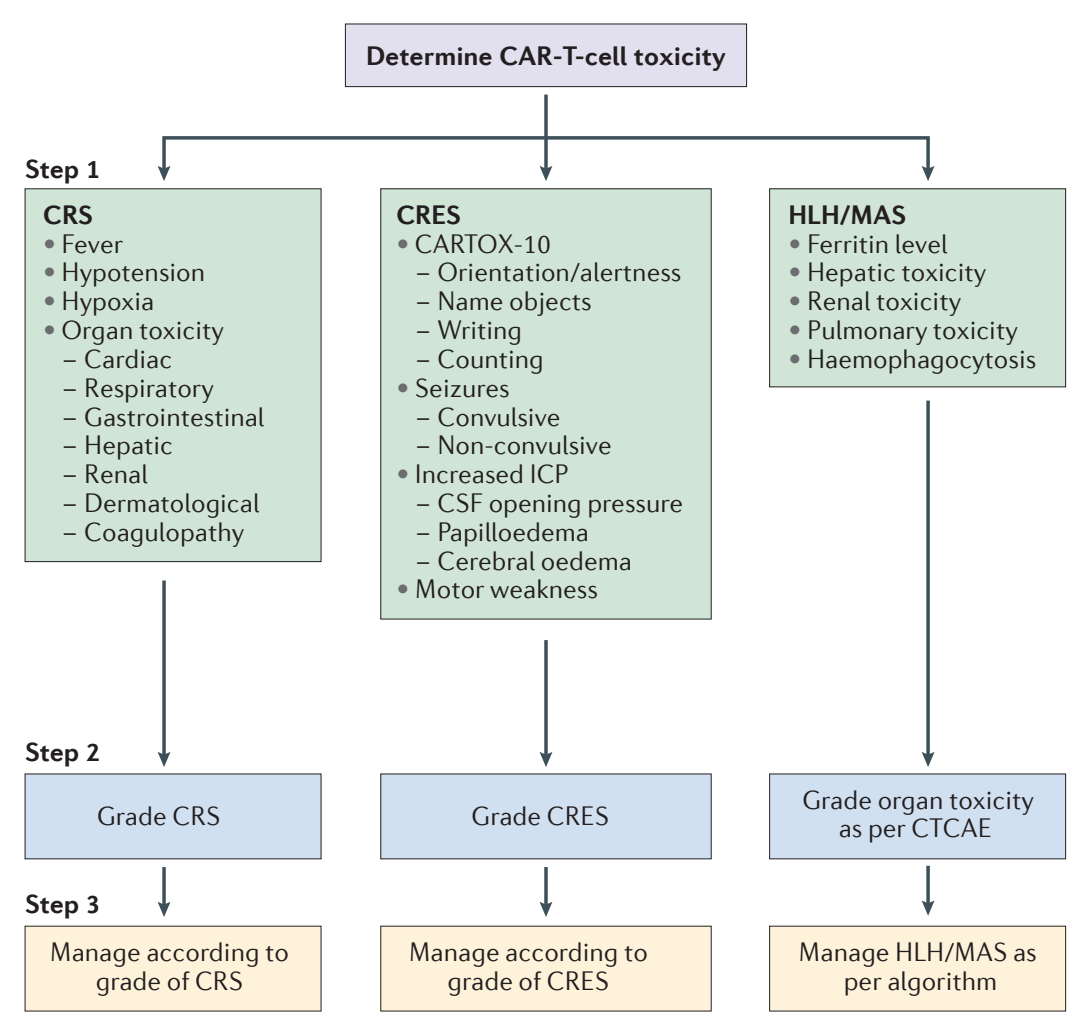

Figure 2 | Three-step approach to the assessment and management of acute toxicities associated with chimeric antigen receptor (CAR)-T-cell therapy. Step 1: the patient's clinical and biological symptoms should be monitored to determine the nature of the CAR-T-cell-related toxicity, in order to diagnose cytokine-release syndrome (CRS), CAR-T-cell-related encephalopathy syndrome (CRES), and haemophagocytic lymphohistiocytosis/macrophage-activation syndrome (HLH/MAS; BOX 5). Step 2: the severity of CRS, CRES, and HLH/MAS should be graded using the criteria provided in TABLE 2, TABLE 4, and the Common Terminology Criteria for Adverse Events, version 4.03 (CTCAE) ${ }^{43}$, respectively. Step 3: the toxicities should be treated according to the management algorithms we have provided for CRS (TABLE 3), CRES (BOX 2), and HLH/MAS (FIG. 3). CARTOX-10, CAR-T-cell-therapy-associated toxicity 10-point neurological assessment; CSF, cerebrospinal fluid; ICP, intracranial pressure.

from CAR-T-cell therapy does not affect objective and complete response rates, nor the durability of responses, although whether long-term efficacy is affected remains unknown ${ }^{24,27}$. Given these concerns, the use of corticosteroids is generally considered only when the toxicities of CAR-T-cell therapy are refractory to anti-IL-6 therapy.

CRS grading. We propose a three-step approach to the management of the major toxicities associated with CAR-T-cell therapy, including CRS: assessment, grading, and treatment (FIG. 2). CRS should be suspected if at least one of the following four symptoms or signs is present within the first 3 weeks of cellular immunotherapy: fever $\geq 38^{\circ} \mathrm{C}$; hypotension with systolic blood pressure $<90 \mathrm{mmHg}$; hypoxia with an arterial oxygen saturation of $<90 \%$ on room air; and/or evidence of organ toxicity ${ }^{30,31}$ (TABLE 2). Some of these symptoms and signs can be caused by other concurrent conditions or therapies; therefore, the health-care provider should use careful clinical judgment to determine whether they are attributable to CRS.
The CRS grade should be determined at least twice daily, and at any time when a change in the patient's status is observed. We recommend that CRS grading is performed using the classification proposed by Lee et al. ${ }^{30}$, with some modifications (TABLE 2). This system is based on four parameters, three of which are vital signs - temperature, blood pressure, and oxygen saturation - and the fourth is the grade of any organ toxicity detected. Grading of organ toxicities is performed according to CTCAE v4.03 (REF. 43). The need for lowdose versus high-dose vasopressor therapy to control hypotension can be used to distinguish grade 2 from grade 3 CRS, according to the definitions of 'high-dose' vasopressors previously reported by Lee and colleagues ${ }^{30}$. Importantly, however, haemodynamic shock in the setting of CRS should be evaluated as a dynamic parameter, and not based on static dose requirements for vasopressors; a patient requiring a rapid increase in the dose of vasopressors, or exhibiting evidence of end-organ hypoperfusion should be treated intensively for grade 3 CRS, even if the vasopressor therapy required is low-dose by definition.

Management of CRS. We recommend management of CRS in accordance with the grade of this toxicity, according to a modified version of the scheme suggested by Lee et al. ${ }^{30}$ (TABLE 3). Grade 1 CRS is primarily managed with supportive care; the use of maintenance intravenous fluids is recommended to keep patients well-hydrated, with special attention to fluid balance in order to avoid pulmonary vascular congestion. In patients with grade 2 CRS, hypotension should be treated promptly with intravenous fluid boluses of $0.9 \%$ normal saline. In addition, anti-IL-6 therapy with tocilizumab or siltuximab is recommended for hypotension that is refractory to fluid boluses (with response rates $>95 \%$ based on our experience), and can be repeated if needed (TABLE 3). If hypotension persists, low-dose vasopressors should be initiated and titrated to achieve a systolic blood pressure of $>90 \mathrm{mmHg}$, and transfer of the patient to an intensive-care unit (ICU) should be considered. Bedside echocardiography to determine ejection fraction is recommended for patients with persistent or repeated episodes of hypotension, because left ventricular dysfunction can occur in patients with CRS ${ }^{30}$. Moreover, non-invasive monitoring of haemodynamic parameters, such as inferior vena cava filling pressures, passive leg raise, pulse pressure, and stroke volume variation, can help guide the management of hypotension, in terms of the need for intravenous fluids, vasopressors, or inotropic agents. Hypoxia associated with either noncardiogenic pulmonary oedema or pleural effusions should be managed with supplemental oxygen and diuresis, or thoracentesis, if indicated. Anti-IL-6 therapy is recommended, and can be repeated as needed, for patients with persistent hypoxia at a fraction of inspired oxygen $\left(\mathrm{FiO}_{2}\right)<40 \%$ and other grade 2 organ toxicities. Other organ toxicities should be managed symptomatically according to standard guidelines. For patients at high risk of severe CRS (grade 3 or 4), or those with persistent grade 2 CRS despite anti-IL-6 therapy, the use of corticosteroids can be considered (TABLE 3). 
Table 3 | Recommendations for the management of cytokine-release syndrome (CRS)

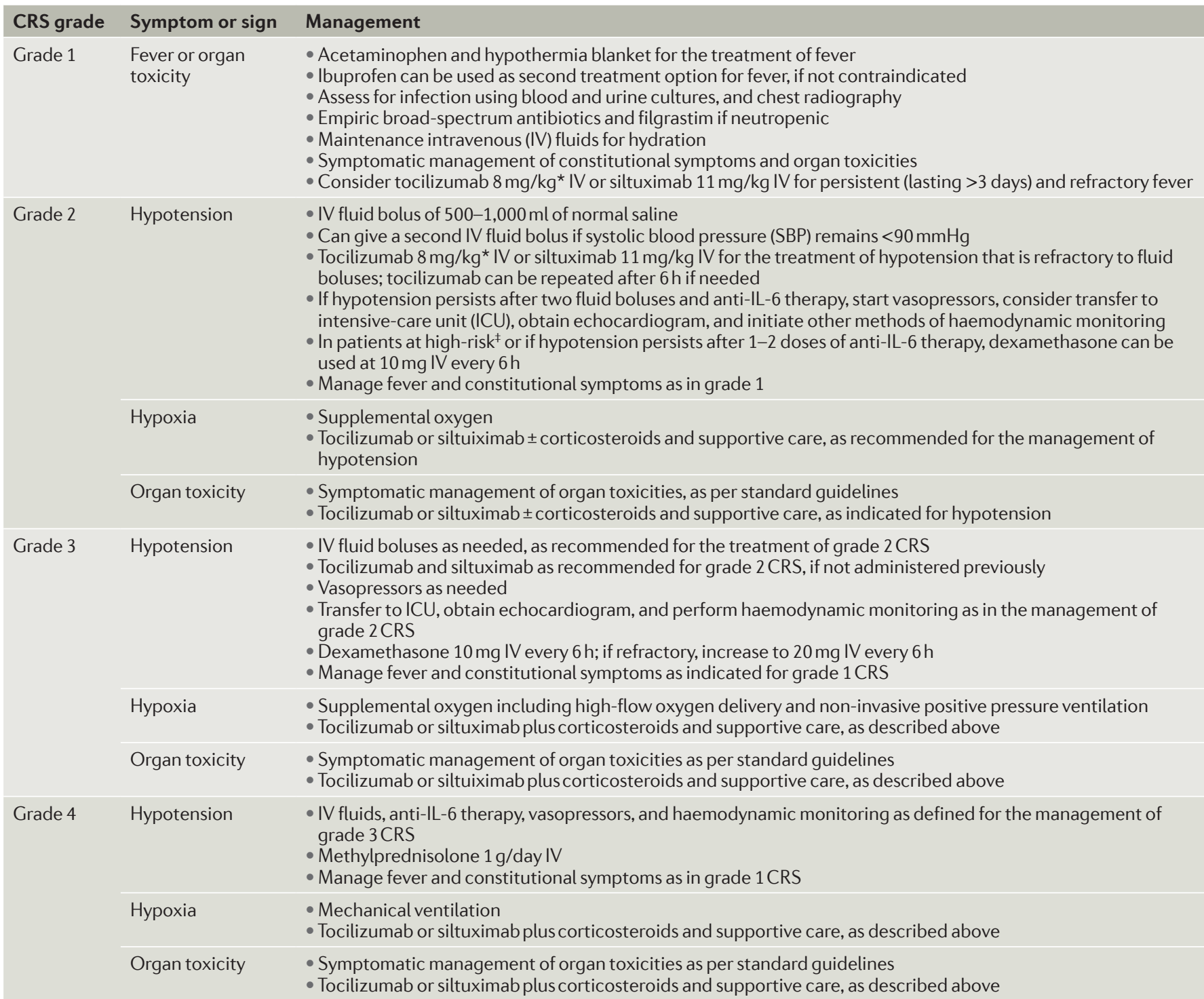

All medication doses indicated are for adults. ${ }^{*}$ Maximum amount of tocilizumab per dose is $800 \mathrm{mg}$. ${ }^{*} H$ igh-risk patients include those with bulky disease, those with comorbidities, and those who develop early onset CRS within 3 days of CAR-T-cell infusion.

Patients with grade 3 or 4 CRS should be treated in the ICU to enable continuous monitoring, management of life-threatening arrhythmias, haemodynamic shock, non-invasive positive pressure ventilation, mechanical ventilation, and/or dialysis (TABLE 3). Both anti-IL-6 therapy and corticosteroids should be used for the management of grades 3 and 4CRS, and the associated organ toxicities. Corticosteroid tapering should be individualized depending on the patient's response and any adverse effects, but is generally recommended to be as rapid as possible. Importantly, the critical care team should be aware of all CAR-T-cell-treated patients in the hospital, in order to facilitate prompt transfers to the ICU, when needed.

Serum CRP levels are a useful marker to monitor in patients undergoing cellular immunotherapy because IL-6 induces the production of CRP by hepatocytes ${ }^{58-60}$. Thus, an increase in serum CRP level is typically detected after the onset of CRS (FIG. 1a), and correlates with increased levels of IL-6 (REFS 10,12,18,30,50). Moreover, the return of CRP levels to baseline indicates that the CRS phase of CAR-T-cell therapy has ended (FIG. 1a), and the patient can be considered for discharge from the hospital, assuming other toxicities that require monitoring and/or intervention have resolved. Of note, the correlation between CRP levels and CRS is variable, and is not observed in all patients. The correlation between serum ferritin levels and CRS is even less consistent. Nevertheless, monitoring ferritin levels can be useful for diagnosis of CAR-T-cell-related HLH/MAS.

\section{Grading and management of CRES} Symptoms and signs of CRES. CRES typically manifests as a toxic encephalopathy, with the earliest signs being diminished attention, language disturbance, 
Table 4 | Grading of CAR-T-cell-related encephalopathy syndrome (CRES)

\begin{tabular}{|c|c|c|c|c|}
\hline Symptom or sign & Grade 1 & Grade 2 & Grade 3 & Grade 4 \\
\hline $\begin{array}{l}\text { Neurological assessment score } \\
\text { (by CARTOX-10*) }\end{array}$ & $\begin{array}{l}7-9 \text { (mild } \\
\text { impairment) }\end{array}$ & $\begin{array}{l}3-6 \text { (moderate } \\
\text { impairment) }\end{array}$ & $0-2$ (severe impairment) & $\begin{array}{l}\text { Patient in critical condition, and/or } \\
\text { obtunded and cannot perform assessment } \\
\text { of tasks }\end{array}$ \\
\hline Raised intracranial pressure & NA & NA & $\begin{array}{l}\text { Stage } 1-2 \text { papilloedema }{ }^{\ddagger} \text {, or CSF } \\
\text { opening pressure }<20 \mathrm{mmHg}\end{array}$ & $\begin{array}{l}\text { Stage } 3-5 \text { papilloedema }{ }^{\ddagger} \text {, or CSF opening } \\
\text { pressure } \geq 20 \mathrm{mmHg} \text {, or cerebral oedema }\end{array}$ \\
\hline Seizures or motor weakness & NA & NA & $\begin{array}{l}\text { Partial seizure, or non-convulsive } \\
\text { seizures on EEG with response to } \\
\text { benzodiazepine }\end{array}$ & $\begin{array}{l}\text { Generalized seizures, or convulsive or } \\
\text { non-convulsive status epilepticus, or new } \\
\text { motor weakness }\end{array}$ \\
\hline \multicolumn{5}{|c|}{$\begin{array}{l}\text { CAR, chimeric antigen receptor; CARTOX-10, CAR-T-cell-therapy-associated toxicity 10-point neurological assessment CSF, cerebrospinal fluid; } \\
\text { EEG, electroencephalogram; NA, not applicable. } \\
\text { *In the CARTOX-10, one point is assigned for each of the following tasks that is performed correctly (normal cognitive function is defined by an overall score of } 10 \text { ): } \\
\text { orientation to year, month, city, hospital, and President/Prime Minister of country of residence (total of } 5 \text { points); name three objects - for example, point to clock, } \\
\text { pen, button (maximum of } 3 \text { points); write a standard sentence, for example, 'our national bird is the bald eagle' (1 point); count backwards from } 100 \text { in tens (1 point) } \\
\text { 'Papilloedema grading is performed according to the modified Frisén scale". }\end{array}$} \\
\hline
\end{tabular}

and impaired handwriting; other symptoms and signs include confusion, disorientation, agitation, aphasia, somnolence, and tremors ${ }^{11,17-20,24,26,27,61-63}$. In severe cases of CRES (grade >2), seizures, motor weakness, incontinence, mental obtundation, increased intracranial pressure, papilloedema, and cerebral oedema can also occur ${ }^{11,17-20,23,61-64}$. In our experience, the manifestation of CRES can be biphasic; the first phase occurs concurrently with high fever and other CRS symptoms, typically within the first 5 days after cellular immunotherapy, and the second phase occurs after the fever and other CRS symptoms subside, often beyond 5 days after cell infusion. Notably, delayed neurotoxicity with seizures or episodes of confusion occurred during the third or fourth week after CAR-T-cell therapy in approximately $10 \%$ of our patients. We have also observed that anti-IL-6 therapy can reverse CRES during the first phase, but is generally not effective in the second phase, when corticosteroids are the preferred treatment. The differential benefit of anti-IL- 6 therapy between the two phases could potentially reflect greater permeability of the blood-brain barrier (BBB) during CRS than at the later post-CRS phase, enabling increased diffusion of the $\mathrm{mAb}$ therapeutics into the brain. CRES typically lasts for 2-4 days, but can vary in duration from a few hours to weeks. In general, CRES occurring concurrently with CRS tends to be of shorter duration and lower grade (grade 1-2) than CRES occurring post-CRS, which is more commonly grade $\geq 3$ and protracted. Moreover, the severity of CRES can fluctuate rapidly, thus, necessitating close patient monitoring. CRES is often disturbing to the patient, their families, and the medical staff, but is generally reversible; although, rare fatal cases have occurred $^{17,18,34,61}$ (TABLE 1).

Pathophysiology of CRES. The pathophysiological mechanism underlying CRES remains to be determined. Two potential explanations can be postulated. Firstly, passive diffusion of cytokines into the brain, supported by the finding that high serum levels of IL- 6 and IL-15 are associated with severe neurotoxicity in patients treated with CAR-T-cell therapy ${ }^{12,24}$. Secondly, trafficking of T cells into the CNS, as indicated by the detection of CAR T cells in cerebrospinal fluid (CSF) from patients with neurotoxicity, in the absence of malignant CNS disease $\mathrm{e}^{5,9,12,33}$. Indeed, in one study ${ }^{12}$, CAR-T-cell numbers were found to be significantly higher in CSF from patients with versus those without neurotoxicity $(P=0.0039)$; the numbers of circulating CAR T cells also tend to be higher in patients who develop neurotoxicity than in those who do not ${ }^{5,9,12,33}$. Of note, protein levels in the CSF are usually elevated in patients with CRES, compared with baseline measurements, suggesting disruption of the $\mathrm{BBB}^{62,63}$. Other organ dysfunction (hepatic and renal), as well as hypoxaemia, and infection, might also contribute to the encephalopathy.

In patients with CRES, secondary cortical irritation is indicated by EEG findings of epileptiform discharges or non-convulsive electrographic seizures. The most-common finding on EEG, in our experience, is diffuse generalized slowing with or without triphasic waves at $1-2 \mathrm{~Hz}$, in keeping with an encephalopathic state. Non-convulsive electrographic seizures should be defined according to published EEG guidelines and on the basis of response to benzodiazepine treatment ${ }^{65,66}$; criteria include repetitive epileptiform discharges with a frequency of $>2.5 \mathrm{~Hz}$, or multifocal frequent epileptiform discharges responding to intravenous benzodiazepines with organized background activity. The incidence of non-convulsive status epilepticus (NCSE) in patients treated with CAR-T-cell therapy is, in our experience, approximately $10 \%$, with some patients $(<5 \%)$ developing NCSE after convulsive status epilepticus. Seizure prophylaxis with levetiracetam $750 \mathrm{mg}$ orally or intravenously every $12 \mathrm{~h}$ is recommended for 30 days, starting on the day of infusion for patients undergoing CAR-T-cell therapies that are known to cause CRES (BOX 1). Levetiracetam is the preferred agent for seizure prophylaxis because it has a better drug-drug interaction profile and lower risk of cardiotoxicity compared with those of other antiepileptic agents, and can be administered safely to patients with hepatic dysfunction; although, dose adjustments might be needed for those with renal dysfunction ${ }^{67}$. Furthermore, cytokine levels are not affected by levetiracetam treatment ${ }^{68}$. Of note, not all CAR or TCR-engineered T-cell products have 


\section{Box 2 | Recommendations for management of CAR-T-cell-related encephalopathy syndrome (CRES)}

\section{Grade 1}

- Vigilant supportive care; aspiration precautions; intravenous (IV) hydration

- Withhold oral intake of food, medicines, and fluids, and assess swallowing

- Convert all oral medications and/or nutrition to IV if swallowing is impaired

- Avoid medications that cause central nervous system depression

- Low doses of lorazepam ( $0.25-0.5 \mathrm{mg}$ IV every $8 \mathrm{~h}$ ) or haloperidol $(0.5 \mathrm{mg}$ IV every $6 \mathrm{~h}$ ) can be used, with careful monitoring, for agitated patients

- Neurology consultation

- Fundoscopic exam to assess for papilloedema

- MRI of the brain with and without contrast; diagnostic lumbar puncture with measurement of opening pressure; MRI spine if the patient has focal peripheral neurological deficits; CT scan of the brain can be performed if MRI of the brain is not feasible

- Daily 30 min electroencephalogram (EEG) until toxicity symptoms resolve; if no seizures are detected on EEG, continue levetiracetam $750 \mathrm{mg}$ every $12 \mathrm{~h}$

- If EEG shows non-convulsive status epilepticus, treat as per algorithm in BOX 3

- Consider anti-IL-6 therapy with tocilizumab $8 \mathrm{mg} / \mathrm{kg}$ *IV or siltuximab $11 \mathrm{mg} / \mathrm{kg}$ IV, if CRES is associated with concurrent cytokine-release syndrome (CRS)

\section{Grade 2}

- Supportive care and neurological work-up as described for grade 1 CRES

- Tocilizumab $8 \mathrm{mg} / \mathrm{kg}$ *IV or siltuximab $11 \mathrm{mg} / \mathrm{kg}$ IV if associated with concurrent CRS

- Dexamethasone $10 \mathrm{mg}$ IV every $6 \mathrm{~h}$ or methylprednisolone $1 \mathrm{mg} / \mathrm{kg}$ IV every $12 \mathrm{~h}$ if refractory to anti-IL-6 therapy, or for CRES without concurrent CRS

- Consider transferring patient to intensive-care unit (ICU) if CRES associated with grade $\geq 2$ CRS

\section{Grade 3}

- Supportive care and neurological work-up as indicated for grade 1 CRES

- ICU transfer is recommended

- Anti-IL-6 therapy if associated with concurrent CRS, as described for grade 2 CRES and if not administered previously

- Corticosteroids as outlined for grade 2 CRES if symptoms worsen despite anti-IL-6 therapy, or for CRES without concurrent CRS; continue corticosteroids until improvement to grade 1 CRES and then taper

- Stage 1 or 2 papilloedema with cerebrospinal fluid (CSF) opening pressure $<20 \mathrm{mmHg}$ should be treated as per algorithm presented in BOX 4

- Consider repeat neuroimaging (CT or MRI) every 2-3 days if patient has persistent grade $\geq 3$ CRES

\section{Grade 4}

- Supportive care and neurological work-up as outlined for grade 1 CRES

- ICU monitoring; consider mechanical ventilation for airway protection

- Anti-IL-6 therapy and repeat neuroimaging as described for grade 3 CRES

- High-dose corticosteroids continued until improvement to grade 1 CRES and then taper; for example, methylprednisolone IV $1 \mathrm{~g} /$ day for 3 days, followed by rapid taper at $250 \mathrm{mg}$ every $12 \mathrm{~h}$ for 2 days, $125 \mathrm{mg}$ every $12 \mathrm{~h}$ for 2 days, and $60 \mathrm{mg}$ every $12 \mathrm{~h}$ for 2 days

- For convulsive status epilepticus, treat as per algorithm in BOX 3

- Stage $\geq 3$ papilloedema, with a CSF opening pressure $\geq 20 \mathrm{mmHg}$ or cerebral oedema, should be treated as per algorithm in BOX 4

All medication doses indicated are for adults. CAR, chimeric antigen receptor. * Maximum amount of tocilizumab per dose is $800 \mathrm{mg}$

been associated with CRES. Thus, for patients undergoing treatment with new agents that have an unknown risk of CRES, seizure prophylaxis can be omitted until data from initial clinical trials have been analysed.

MRI and CT scans of the brain are usually negative for any anatomical pathology that would account for the neurotoxicity symptoms observed in patients treated with CAR-T-cell therapy, although rare cases of reversible T2/fluid attenuated inversion recovery (FLAIR) MRI hyperintensity involving the thalami, dorsal pons, and medulla ${ }^{62}$, and cerebral oedema have been reported ${ }^{19,33,64,64,69,70}$. Of note, life-threatening cerebral oedema, although very rare in patients treated with cellular immunotherapy, tends to have a very rapid course with ensuing brain death within $24 \mathrm{~h}^{19,33,64,64,69,70}$. Notably, in March 2017, five deaths attributed to cerebral oedema were reported following treatment of the patients with one anti-CD19 CAR-T-cell product (JCAR015) as part of a multicentre clinical trial ${ }^{64,69}$. The sponsor has now halted development of this agent ${ }^{64,69}$. Why deaths relating to cerebral oedema have been observed with certain anti-CD19 CAR-T-cell products ${ }^{19,33,64,64,69,70}$ (TABLE 1), 
Box 3 | Recommendations for the management of status epilepticus after CAR-T-cell therapy

Non-convulsive status epilepticus

- Assess airway, breathing, and circulation; check blood glucose

- Lorazepam* $0.5 \mathrm{mg}$ intravenously (IV), with additional $0.5 \mathrm{mg}$ IV every $5 \mathrm{~min}$, as needed, up to a total of $2 \mathrm{mg}$ to control electrographical seizures

- Levetiracetam $500 \mathrm{mg}$ IV bolus, as well as maintenance doses

- If seizures persist, transfer to intensive-care unit (ICU) and treat with phenobarbital loading dose of $60 \mathrm{mg}$ IV

- Maintenance doses after resolution of non-convulsive status epilepticus are as follows: lorazepam $0.5 \mathrm{mg} I V$ every $8 \mathrm{~h}$ for three doses; levetiracetam 1,000 mg IV every $12 \mathrm{~h}$; phenobarbital $30 \mathrm{mg} I V$ every $12 \mathrm{~h}$

Convulsive status epilepticus

- Assess airway, breathing, and circulation; check blood glucose

- Transfer to ICU

- Lorazepam* $2 \mathrm{mg} I \mathrm{~V}$, with additional $2 \mathrm{mg} I \mathrm{~V}$ to a total of $4 \mathrm{mg}$ to control seizures

- Levetiracetam $500 \mathrm{mg}$ IV bolus, as well as maintenance doses

- If seizures persist, add phenobarbital treatment at a loading dose of $15 \mathrm{mg} / \mathrm{kg}$ IV

- Maintenance doses after resolution of convulsive status epilepticus are: lorazepam $0.5 \mathrm{mg}$ IV every $8 \mathrm{~h}$ for three doses; levetiracetam $1,000 \mathrm{mg} I V$ every $12 \mathrm{~h}$; phenobarbital $1-3 \mathrm{mg} / \mathrm{kg}$ IV every $12 \mathrm{~h}$

- Continuous electroencephalogram monitoring should be performed, if seizures are refractory to treatment

All indicated doses of medication are for adult patients. CAR, chimeric antigen receptor. *Lorazepam is the recommended benzodiazepine because it is short-acting, compared with diazepam, and has been widely used in the management of seizures.

but not others, remains unclear. Additional investigations are needed to better understand the pathophysiology of this fatal complication, for which anti-IL-6 therapy is not effective, ${ }^{9,64}$.

Grading of CRES. Similar to other organ toxicities, CRES has been graded according to the CTCAE v4.03 (REF. 43), in terms of level of consciousness, orientation, ability to perform activities of daily living (in the context of encephalopathy), speech, tremors, seizures, incontinence, and motor weakness. The CTCAE grading system does not, however, adequately quantify the acute neurological deficits that seem to be unique toxicities of CAR-T-cell therapies. Thus, we have developed a new grading system for CRES, together with the CARTOX 10-point neurological assessment (CARTOX-10) tool (TABLE 4). We formulated this tool based on our experiences in the observation and treatment of more than 50 adult patients with grade $1-5$ neurotoxicity from CAR-T-cell therapy, approximately $50 \%$ of whom developed grade $\geq 3$ neurological adverse events. The CARTOX-10 incorporates some of the key elements of the 30-point MMSE, encompassing the predominant alterations in concentration, speech, and writing ability that are associated with CRES, to enable evaluation of the acute neurotoxic events observed in patients treated with CAR T cells using a 10-point scale. In the CARTOX-10, one point is assigned for each of the following tasks that is performed correctly: orientation to year, month, city, hospital, and President/Prime Minister of country of residence (total of 5 points); naming three objects (maximum of 3 points); writing a standard sentence (1 point); counting backwards from 100 in tens (1 point). Normal cognitive function is defined by an overall score of 10 . In comparison with the MMSE, which is used to screen patients for dementia (not delirium), the CARTOX-10 is simple to use, and can be performed rapidly and repeatedly several times a day by all health-care providers, including nurses and physicians. The tasks used in the CARTOX-10 can be simplified depending on the education level of the patient, but need to be documented, together with a baseline score, before CAR-T-cell infusion, to ensure that follow-up assessments are reliable and consistent; however, this tool is primarily designed for the assessment of adult patients, and alternative tools need to be developed to assess children. We recommend that the 10-point neurological assessment be performed every $8 \mathrm{~h}$ while the patient is hospitalized after CAR-T-cell therapy. Any change from a normal score should prompt thorough investigation as described in the following section of this manuscript. Patients who are aphasic (CARTOX-10 score of 0), but awake/arousable and without other neurological symptoms or signs (such as motor weakness, seizures and papilloedema), are considered to have grade 3 CRES.

In addition to the CARTOX-10, parameters including papilloedema, CSF opening pressure, and imaging assessment were incorporated into our CRES grading system (TABLE 4), in order to detect signs of raised intracranial pressure and cerebral oedema. In contrast with the CTCAE v4.03 (REF. 43), seizures are upgraded to a grade 3 or 4 adverse event in the proposed CRES grading system (TABLE 4). Thus, the advantages of this grading system over the CTCAE include greater objectivity and ease of application.

Management of CRES. Similar to CRS, the management of CRES is based on the toxicity grade (BOX 2). Grade 1 CRES is primarily managed with supportive care. The head of the patient's bed should be elevated by at least 30 degrees to minimize aspiration risks and to improve cerebral venous flow. A neurology consultation should be requested for thorough neurological evaluation, including EEG and fundoscopic 
examination to rule out papilloedema, of all patients with CRES, regardless of grade. Assessment for papilloedema can be difficult in restless patients with non-dilated pupils. Neuroimaging and CSF opening pressure, if available, are much better surrogates of increased intracranial pressure and possible cerebral oedema than papilloedema; however, lumbar puncture might also be infeasible when patients are restless or have coagulopathy. In patients with an ommaya reservoir, opening pressure can be measured in the supine position with the base of the manometer placed at heart level. Combinations of these techniques should be considered to diagnose increased intracranial pressure and cerebral oedema. In particular, repeated neuroimaging, preferably with review of the results by a neuroradiologist, is recommended to detect early signs of cerebral oedema in patients with grade 3 or 4 CRES, and in patients with rapid changes in the CRES grade (increase in grade by two levels, for example, grade 1 CRES worsening to grade 3 ). The clinical status of the patient often dictates the choice of neuroimaging modality: MRI of the brain is preferred, but cannot be performed for unstable or agitated patients, whereas CT can be. In our experience (relating to four cases in $\sim 50$ patients with CRES), the development of cerebral oedema in patients treated with CAR T cells is associated with other acute and clinically significant neurological changes, such as a low CARTOX-10 score and/or seizures.

Anti-IL- 6 therapy is recommended for patients with grade $\geq 1$ CRES with concurrent CRS; if not associated with CRS, corticosteroids are the preferred treatment for grade $\geq 2$ CRES, and can be tapered after improvement of CRES to grade 1 (BOX 2). The optimal duration of corticosteroid therapy remains unknown, although in our experience, short courses of steroids have been associated with resolution of neurological toxicities without impaired antitumour responses ${ }^{24,27}$. Patients should be monitored closely for recurrence of neurotoxicity symptoms during corticosteroid tapering. Monitoring in the ICU is recommended for patients with grade 3 CRES, and is required for all patients with grade 4 CRES because they might need mechanical ventilation for airway protection (BOX 2). Non-convulsive and convulsive status epilepticus in these patients should be managed with benzodiazepines and additional antiepileptics (preferably with levetiracetam), as needed (BOX 3). The response of some patients to benzodiazepine is rapid, with improvements in both EEG findings and mental status. After levetiracetam, phenobarbital is the preferred second antiepileptic for the management of CRES-related seizures: phenytoin and lacosamide are associated with higher risks of cardiovascular adverse effects, therefore, their use in patients with concurrent CRS should be excluded to avoid arrhythmias and hypotension. Grade 3 CRES with raised intracranial pressure (TABLE 4) should be managed promptly with corticosteroids and acetazolamide (BOX 4); patients who develop grade 4 CRES with cerebral oedema (TABLE 4) should receive high-dose corticosteroids, hyperventilation, and hyperosmolar therapy (BOX 4).

\section{CAR-related HLH grading and management}

HLH/MAS encompasses a group of severe immunological disorders characterized by hyperactivation of macrophages and lymphocytes, proinflammatory cytokine production, lymphohistiocytic tissue infiltration,

\section{Box 4 | Recommendation for management of raised intracranial pressure (ICP) after CAR-T-cell therapy}

Stage 1 or 2 papilloedema* with cerebrospinal fluid (CSF) opening pressure of $<20 \mathrm{mmHg}$ without cerebral oedema

- Acetazolamide 1,000 mg intravenously (IV), followed by 250-1,000 mg IV every $12 \mathrm{~h}$ (adjust dose based on renal function and acid-base balance, monitored 1-2 times daily)

Stage 3,4 , or 5 papilloedema*, with any sign of cerebral oedema on imaging studies, or a CSF opening pressure of $\geq 20 \mathrm{mmHg}$

- Use high-dose corticosteroids with methylprednisolone IV 1 g/day, as recommended for grade 4 CAR-T-cell-related encephalopathy syndrome (CRES; BOX 2)

- Elevate head end of the patient's bed to an angle of 30 degrees

- Hyperventilation to achieve target partial pressure of arterial carbon dioxide $\left(\mathrm{PaCO}_{2}\right)$ of $28-30 \mathrm{mmHg}$, but maintained for no longer than $24 \mathrm{~h}$

- Hyperosmolar therapy with either mannitol ( $20 \mathrm{~g} / \mathrm{dl}$ solution) or hypertonic saline ( $3 \%$ or $23.4 \%$, as detailed below) - Mannitol: initial dose $0.5-1 \mathrm{~g} / \mathrm{kg}$; maintenance at $0.25-1 \mathrm{~g} / \mathrm{kg}$ every $6 \mathrm{~h}$ while monitoring metabolic profile and serum osmolality every $6 \mathrm{~h}$, and withhold mannitol if serum osmolality is $\geq 320 \mathrm{mOsm} / \mathrm{kg}$, or the osmolality gap is $\geq 40$ - Hypertonic saline: initial $250 \mathrm{ml}$ of $3 \%$ hypertonic saline; maintenance at $50-75 \mathrm{ml} / \mathrm{h}$ while monitoring electrolytes every $4 \mathrm{~h}$, and withhold infusion if serum Na levels reach $\geq 155 \mathrm{mEq} / \mathrm{l}$

- For patients with imminent herniation: initial $30 \mathrm{ml}$ of $23.4 \%$ hypertonic saline; repeat after $15 \mathrm{~min}$, if needed

- If patient has ommaya reservoir, drain CSF to target opening pressure of $<20 \mathrm{mmHg}$

- Consider neurosurgery consultation and IV anaesthetics for burst-suppression pattern on electroencephalography

- Metabolic profiling every $6 \mathrm{~h}$ and daily CT scan of head, with adjustments in usage of the aforementioned medications to prevent rebound cerebral oedema, renal failure, electrolyte abnormalities, hypovolemia, and hypotension

All medication doses indicated are for adults. CAR, chimeric antigen receptor. *Papilloedema grading should be performed according to the modified Frisén scale ${ }^{98}$. 


\section{Box 5 | Diagnostic criteria for CAR-T-cell-related HLH/MAS}

A patient might have HLH/MAS if he/she had a peak serum ferritin level of $>10,000 \mathrm{ng} /$ $\mathrm{ml}$ during the cytokine-release syndrome phase of CAR-T-cell therapy (typically the first 5 days after cell infusion) and subsequently developed any two of the following:

- Grade $\geq 3$ increase in serum bilirubin, aspartate aminotransferase, or alanine aminotransferase levels*

- Grade $\geq 3$ oliguria or increase in serum creatinine levels*

- Grade $\geq 3$ pulmonary oedema*

- Presence of haemophagocytosis in bone marrow or organs based on histopathological assessment of cell morphology and/or CD68 immunohistochemistry

CAR, chimeric antigen receptor; $\mathrm{HLH}$, haemophagocytic lymphohistiocytosis; MAS, macrophage-activation syndrome. ${ }^{*}$ Grading as per Common Terminology Criteria for Adverse Events, version 4.03 (REF. 43) reverse HLH/MAS arising in a patient after blinatum$\mathrm{omab}^{42}$. If the patient has no improvement clinically or serologically within $48 \mathrm{~h}$, additional therapy with etoposide $75-100 \mathrm{mg} / \mathrm{m}^{2}$ should be considered, as the available evidence in contexts other than CAR-T-cell therapy indicates that this agent is the preferred treatment for refractory $\mathrm{HLH}^{71,74,77}$. Moreover, this agent can be used in patients with liver and kidney dysfunction ${ }^{71,74,77}$. Indeed, rapid initiation of etoposide therapy, in spite of organ dysfunction, is imperative for patients with high probability of a HLH diagnosis ${ }^{76}$, owing to the high risk of death ${ }^{74,75}$. Etoposide can be repeated after 4-7 days, as indicated clinically or serologically, to achieve adequate disease control. Intrathecal cytarabine, with or without hydrocortisone, should also be considered for patients with HLH-associated neurotoxicity (FIG. 3). Although etoposide and cytarabine are often used in the treatment of familial and malignancy-associated $\mathrm{HLH}^{71,74,77}$, at present, direct evidence to support their use in patients with CAR-T-cell-associated HLH is lacking.

Broadly, the goal of therapy for HLH is to suppress overactive $\mathrm{CD}^{+} \mathrm{T}$ cells and macrophages that orchestrate this immunological syndrome; however, the current treatments do not specifically target these cell types. In the near future, specific cytokines that play a central part in HLH/MAS, such as IFN $\gamma$, will cytokines (such as IFN $\gamma$ and IL-6); and low serum levels of fibrinogen ${ }^{24,32,34,35,71-73}$. Thus, CRS and HLH/MAS might belong to a similar spectrum of systemic hyperinflammatory disorders. Whereas patients with CRS usually respond to supportive care, anti-IL-6 therapies, and corticosteroid treatment, fulminant and refractory HLH/MAS, in our experience, is observed in $\sim 1 \%$ of all patients treated with CAR-T-cell therapy, and necessitates additional therapy. Indeed, refractory HLH/MAS is associated with high mortality if not treated promptly ${ }^{74,75}$; however, the diagnosis of HLH/MAS can be difficult in the context of CRS. Many of the traditional diagnostic criteria for HLH/MAS - fever, splenomegaly, cytopenias in at least two of three haematopoietic cell lineages (red blood cells, white blood cells, and platelets), hypertriglyceridemia or hypofrinogenaemia with elevated D-dimers, haemophagocytosis in bone marrow, hyperferritinaemia, high levels of soluble CD25, and low or absent NK-cell activity - are not specific. Indeed, these features are frequently present in patients with even low-grade CRS and also in those with advanced-stage haematological malignancies in the absence of CAR-T-cell ther$\mathrm{apy}^{76}$. Thus, new criteria are needed for the diagnosis of HLH/MAS in patients with CRS after CAR-T-cell therapy.

We propose that a diagnosis of CAR-T-cell-related HLH/MAS should be made if the patient has had peak ferritin levels of $>10,000 \mathrm{ng} / \mathrm{ml}$ during the CRS phase (typically within the first 5 days after cell infusion), and has developed any two of the following: grade $\geq 3$ organ toxicities involving the liver, kidney, or lung, or haemophagocytosis in the bone marrow or other organs (BOX 5). Patients with suspected HLH/MAS should be managed with anti-IL- 6 therapy and corticosteroids for grade $\geq 3$ organ toxicities as per the CRS recommendations (TABLE 3; FIG. 3). Cytokine-directed therapy has been demonstrated to

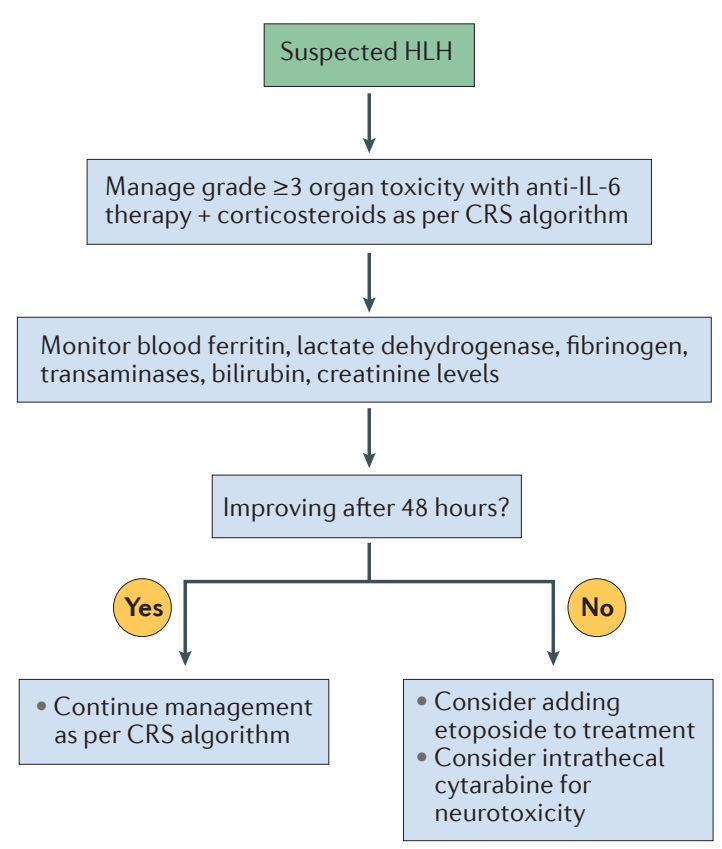

Figure 3 | Recommendations for the management of Chimeric antigen receptor (CAR)-T-cell-related haemophagocytic lymphohistiocytosis/macrophageactivation syndrome (HLH/MAS). HLH/MAS should initially be managed according to the guidelines for cytokine-release syndrome (CRS; TABLE 3), with appropriate subsequent laboratory testing to monitor response to treatment. If the results of these tests reveal no improvement within $48 \mathrm{~h}$, escalation of treatment should be considered. 
probably be targetable using agents in clinical development. For example, a humanized anti-IFN $\gamma \mathrm{mAb}$, NI-0501, produced responses in nine of 13 children with refractory primary HLH (69\%), with good tolerability ${ }^{78}$.

\section{Future directions}

CAR-T-cell therapies offer the promise to improve clinical outcomes and induce remissions in patients with refractory cancers; however, the unique acute toxicities of these agents, which can be fatal, require intensive monitoring and prompt management. Many factors probably affect the onset, peak level, duration, and type of acute toxicity that will occur after treatment with various CAR-T-cell products, and this variability should be considered when monitoring and treating each patient. Such factors might include: the nature of the conditioning chemotherapy; the design of the CAR construct; CAR-T-cell dose; the cellular composition of the CAR-T-cell product; the manufacturing process used to generate the CAR T cells; and host characteristics, including the type of malignancy, tumour burden, patient age, and sites of disease.

Systematic investigations are necessary to define predictors of efficacy and toxicity, and to determine whether current interventions, such as anti-IL-6 therapies and corticosteroids, affect the efficacy of CAR-T-cell therapy. Such studies might also identify novel biomarkers of severe toxicity and lead to the development of prophylactic strategies to further improve the safety of treatment. Indeed, the peak level of serum IFN $\gamma$ after CAR-T-cell therapy is positively correlated with the severity of CRS ${ }^{12,17,18,34}$; therefore, IFN $\gamma$ could potentially be another important therapeutic target for the management of CRS in the future, although the possibility that blocking this cytokine will affect antitumour efficacy is a concern. Similarly, peak levels of serum IL-6 are associated with severe CAR-T-cell-related neurotoxicity ${ }^{12,17,18,24,63}$; as IL- 6 antagonists are not expected to cross the BBB, however, investigation of intrathecal administration of these agents is warranted for the management of CRES. Other approaches that are currently being tested in preclinical and clinical studies to improve the safety of CAR-T-cell therapies include the integration of genetic constructs containing 'safety (suicide) switches' or 'elimination genes' that can be activated or targeted in order to eliminate the CAR T cells when life-threatening toxicities develop ${ }^{50,79-85}$. An alternative strategy is to use 'remote-controlled' CARs, whereby an inducible gene-regulatory system enables controlled expression of CARs upon drug administration ${ }^{86}$.

Whereas such approaches might enhance the safety of CAR-T-cell therapies, combination strategies with immune-checkpoint blockade have the potential to increase the antitumour activity and persistence CAR T cells, but also to increase their toxicity. Furthermore, CAR-T-cell therapies will probably be associated with 'on-target, off-tumour' effects if the target antigen is expressed on nonmalignant cells. This situation has been well recognized with anti-CD19 CAR-T-cell therapy, which can cause protracted B-cell aplasia and hypogammaglobulinemia ${ }^{3,9,11,22,23}$. Non-malignant B cells are expendable, however, because hypogammaglobulinaemia is easily corrected with intravenous immunoglobulin replacement therapy. By contrast, if the target antigen for CAR T cells is present in non-malignant tissues of vital organs, treatment with these agents might lead to severe and possibly fatal toxicity ${ }^{87}$. Indeed, this possibility of on-target, off-tumour toxicity is the greatest obstacle for the successful development of CAR-T-cell therapies for solid malignancies. This limitation has been underscored by the report of fatal respiratory failure and multiorgan dysfunction in a patient treated with HER2-specific CAR T cells (TABLE 1), which was hypothesized to be an on-target, off-tumour effect resulting from expression of the target antigen in lung tissue $^{88}$; however, this death might have been related, at least in part, to the high dose of CAR T cells used (a total of $1 \times 10^{10}$ cells were infused) ${ }^{88}$, because lowerdose HER2-target CAR-T-cell therapy $\left(1 \times 10^{4}-1 \times 10^{8} / \mathrm{m}^{2}\right.$ cells) has been demonstrated to be tolerable in another trial $^{89}$. Other factors, such as the omission of lymphodepleting chemotherapy, non-inclusion of supplementary IL-2, the absence of a 4-1BB co-stimulatory domain in the CAR molecule, or the use of a different anti-HER2 scFv, might also have contributed to the lower toxicity observed in the latter trial ${ }^{89}$. In other clinical studies, the treatment of patients with CAR T cells targeting carcinoembryonic antigen caused colitis ${ }^{90}$, and the use of CAR T cells targeting carbonicanhydrase-IX resulted in cholestasis ${ }^{91,92}$. An acute hypersensitivity reaction with anaphylaxis has also been described in one patient who received multiple infusions of mesothelin-specific CAR T cells ${ }^{93}$; however, the researchers concluded that this adverse effect was attributable to the development of human anti-mouse antibodies targeting the murine $\mathrm{mAb}$ components of the CAR construct ${ }^{93}$. Together, these observations emphasize that vigilant monitoring and expectation of the unexpected is necessary when evaluating any novel CAR-T-cell or transgenic TCR-based therapy, including evaluations of novel conditioning regimens, novel CAR or TCR constructs, novel targets, and novel treatment combinations. We also advocate the development of customized tracking tools in electronic health-record systems to monitor and grade these toxicities (Supplementary information S2 (table)).

\section{Conclusions}

The recommendations provided herein are meant to serve as a framework for the assessment and management of toxicities associated with CAR-T-cell therapies, but can also be used for TCR-gene therapies, CAR-NK-cell therapies, and potentially BiTE therapies that can cause similar adverse events ${ }^{36-42}$. While appropriate given our current knowledge and experience, these recommendations are expected to be modified and evolve as we increase our understanding of the pathophysiology of these toxicities, the determinants of durable antitumour responses, and the effects of interventions used to manage toxicities of these promising novel therapies. 
1. Rosenberg, S. A. \& Restifo, N. P. Adoptive cell transfer as personalized immunotherapy for human cancer. Science 348, 62-68 (2015)

2. June, C. H., Riddell, S. R. \& Schumacher, T. N. Adoptive cellular therapy: a race to the finish line. Sci. Transl Med. 7, 280 ps7 (2015).

3. Kochenderfer, J. N. et al. Eradication of B-lineage cells and regression of lymphoma in a patient treated with autologous $T$ cells genetically engineered to recognize CD19. Blood 116, 4099-4102 (2010).

4. Porter, D. L., Levine, B. L., Kalos, M., Bagg, A. \& June, C. H. Chimeric antigen receptor-modified T cells in chronic lymphoid leukemia. N. Engl. J. Med. 365, 725-733 (2011).

5. Grupp, S. A. et al. Chimeric antigen receptor-modified T cells for acute lymphoid leukemia. N. Engl. J. Med. 368, 1509-1518 (2013).

6. Brentjens, R. J. et al. CD 19-targeted T cells rapidly induce molecular remissions in adults with chemotherapy-refractory acute lymphoblastic leukemia. Sci. Transl Med. 5, 177ra138 (2013).

7. Cruz, C. R. et al. Infusion of donor-derived CD19-redirected virus-specific T cells for B-cell malignancies relapsed after allogeneic stem cell transplant: a phase 1 study. Blood 122, 2965-2973 (2013).

8. Kochenderfer, J. N. et al. Donor-derived CD19-targeted T cells cause regression of malignancy persisting after allogeneic hematopoietic stem cell transplantation. Blood 122, 4129-4139 (2013).

9. Maude, S. L. et al. Chimeric antigen receptor T cells for sustained remissions in leukemia. N. Engl. J. Med. 371, 1507-1517 (2014)

10. Davila, M. L. et al. Efficacy and toxicity management of $19-28 z$ CAR T cell therapy in B cell acute lymphoblastic leukemia. Sci. Transl Med. 6, 224 ra225 (2014).

11. Kochenderfer, J. N. et al. Chemotherapy-refractory diffuse large B-cell lymphoma and indolent B-cell malignancies can be effectively treated with autologous T cells expressing an anti-CD 19 chimeric antigen receptor. J. Clin. Oncol. 33, 540-549 (2015).

12. Lee, D. W. et al. T cells expressing CD19 chimeric antigen receptors for acute lymphoblastic leukaemia in children and young adults: a phase 1 doseescalation trial. Lancet 385, 517-528 (2015).

13. Garfall, A. L. et al. Chimeric antigen receptor T cells against CD 19 for multiple myeloma. N. Engl. J. Med. 373, 1040-1047 (2015)

14. Fraietta, J. A. et al. Ibrutinib enhances chimeric antigen receptor T-cell engraftment and efficacy in leukemia. Blood 127, 1117-1127 (2016).

15. Brudno, J. N. et al. Allogeneic T cells that express an anti-CD 19 chimeric antigen receptor induce remissions of B-cell malignancies that progress after allogeneic hematopoietic stem-cell transplantation without causing graft-versus-host disease. J. Clin Oncol 34, 1112-1121 (2016).

16. Kebriaei, P. et al. Phase I trials using Sleeping Beauty to generate CD19-specific CAR T cells. J. Clin. Invest. 126, 3363-3376 (2016)

17. Turtle, C. J. et al. CD19 CAR-T cells of defined $\mathrm{CD}^{+}: \mathrm{CD} 8^{+}$composition in adult B cell ALL patients. J. Clin. Invest. 126, 2123-2138 (2016).

18. Turtle, C. J. et al. Immunotherapy of non-Hodgkin's lymphoma with a defined ratio of $\mathrm{CD} 8^{+}$and $\mathrm{CD} 4^{+}$ CD 19-specific chimeric antigen receptor-modified T cells. Sci. Transl Med. 8, 355ra116 (2016).

19. Turtle, C. J. et al. Durable molecular remissions in chronic lymphocytic leukemia treated with CD19-specific chimeric antigen receptor-modified $\mathrm{T}$ cells after failure of ibrutinib. J. Clin. Oncol. http://dx.doi.org/10.1200/JCO.2017.72.8519 (2017).

20. Kochenderfer, J. N. et al. Lymphoma remissions caused by anti-CD 19 Chimeric antigen receptor $t$ cells are associated with high serum interleukin-15 levels. J. Clin. Oncol. 35, 1803-1813 (2017).

21. Hinrichs, C. S. \& Rosenberg, S. A. Exploiting the curative potential of adoptive T-cell therapy for cancer Immunol. Rev. 257, 56-71 (2014).

22. Kochenderfer, J. N. et al. B-Cell depletion and remissions of malignancy along with cytokineassociated toxicity in a clinical trial of anti-CD 19 chimeric-antigen-receptor-transduced T cells. Blood 119, 2709-2720 (2012).

23. Locke, F. L. et al. Phase 1 results of ZUMA-1: a multicenter study of KTE-C19 anti-CD 19 CAR T Cell therapy in refractory aggressive lymphoma. Mol. Ther. 25, 285-295 (2017).
24. Neelapu, S. S. et al. KTE-C19 (anti-CD19 CAR T cells) induces complete remissions in patients with refractory diffuse large B-cell lymphoma (DLBCL): results from the pivotal phase 2 ZUMA-1 [abstract]. Blood 128, LBA-6 (2016).

25. Grupp, S. A. et al. Analysis of a Global registration trial of the efficacy and safety of CTL019 in pediatric and young adults with relapsed/refractory acute lymphoblastic leukemia (ALL) [abstract]. Blood 128, 221 (2016).

26. Schuster S J et al. Global pivotal phase 2 trial of the CD 19-targeted therapy CTLO19 in adult patients with relapsed or refractory $(\mathrm{R} / \mathrm{R})$ diffuse large $\mathrm{B}$-cell lymphoma (DLBCL) - an interim analysis [abstract]. Hematol. Oncol. 35 (Suppl. S2), 27 (2017).

27. Neelapu, S. S. et al. Axicabtagene ciloleucel (Axi-cel; KTE-C19) in patients with refractory aggressive nonHodgkin lymphomas (NHL): primary results of the pivotal trial ZUMA-1 [abstract]. Hematol. Oncol. 35 (Suppl. S2), 28 (2017).

28. Abramson, J. et al. High CR rates in relapsed/ refractory $(\mathrm{R} / \mathrm{R})$ aggressive $\mathrm{B}-\mathrm{NHL}$ treated with the CD19-directed CAR T cell product JCAR017 (TRANSCEND NHL 001) [abstract]. Hematol. Oncol. 35 (Suppl. S2), 138 (2017)

29. Ali, S. A. et al. T cells expressing an anti-B-cell maturation antigen chimeric antigen receptor cause remissions of multiple myeloma. Blood 128 1688-1700 (2016)

30. Lee, D. W. et al. Current concepts in the diagnosis and management of cytokine release syndrome. Blood 124, 188-195 (2014)

31. Brudno, J. N. \& Kochenderfer, J. N. Toxicities of chimeric antigen receptor T cells: recognition and management. Blood 127, 3321-3330 (2016).

32. Maude, S. L., Barrett, D., Teachey, D. T. \& Grupp, S. A Managing cytokine release syndrome associated with novel T cell-engaging therapies. Cancer J. 20 119-122 (2014).

33. Hu, Y. et al. Predominant cerebral cytokine release syndrome in CD19-directed chimeric antigen receptormodified T cell therapy. J. Hematol. Oncol. 9, 70 (2016).

34. Teachey, D. T. et al. Identification of predictive biomarkers for cytokine release syndrome after chimeric antigen receptor T-cell therapy for acute lymphoblastic leukemia. Cancer Discov. 6, 664-679 (2016)

35. Ishii, K. et al. Tocilizumab-refractory cytokine release syndrome (CRS) triggered by chimeric antigen receptor (CAR)-transduced T cells may have distinct cytokine profiles compared to typical CRS. Blood $\mathbf{1 2 8}$, 3358 (2016)

36. Robbins, P. F. et al. Tumor regression in patients with metastatic synovial cell sarcoma and melanoma using genetically engineered lymphocytes reactive with NY-ESO-1. J. Clin. Oncol. 29, 917-924 (2011).

37. Koestner, W. et al. PD-L1 blockade effectively restores strong graft-versus-leukemia effects without graft-versus-host disease after delayed adoptive transfer of T-cell receptor gene-engineered allogeneic CD8+ T cells. Blood 117, 1030-1041 (2011).

38. Romanski, A. et al. CD19-CAR engineered NK-92 cells are sufficient to overcome NK cell resistance in B-cell malignancies. J. Cell. Mol. Med. 20, 1287-1294 (2016).

39. Han, J. et al. CAR-engineered NK cells targeting wild type EGFR and EGFRvIII enhance killing of glioblastoma and patient-derived glioblastoma stem cells. Sci. Rep. 5, 11483 (2015).

40. Bargou, R. et al. Tumor regression in cancer patients by very low doses of a $\mathrm{T}$ cell-engaging antibody. Science 321, 974-977 (2008).

41. Topp, M. S. et al. Safety and activity of blinatumomab for adult patients with relapsed or refractory B-precursor acute lymphoblastic leukaemia: a multicentre, single-arm, phase 2 study. Lancet Oncol. 16, 57-66 (2015)

42. Teachey, D. T. et al. Cytokine release syndrome after blinatumomab treatment related to abnormal macrophage activation and ameliorated with cytokinedirected therapy. Blood 121, 5154-5157 (2013).

43. U.S. Department of Health \& Human Services. Common Terminology Criteria for Adverse Events (CTCAE) Version 4.0 https://evs.nci.nih.gov/ftp $1 /$ CTCAE/CTCAE 4.03 2010-06-14 QuickReference 5x7.pdf (2010)

44. Frey, N. V. et al. Refractory cytokine release syndrome in recipients of chimeric antigen receptor (CAR) T cells. Blood 124, 2296-2296 (2014).
45. Rose-John, S. IL-6 trans-signaling via the soluble IL-6 receptor: importance for the pro-inflammatory activities of IL-6. Int. J. Biol. Sci. 8, 1237-1247 (2012).

46. Scheller, J., Chalaris, A., Schmidt-Arras, D. \& RoseJohn, $\mathrm{S}$. The pro- and anti-inflammatory properties of the cytokine interleukin-6. Biochim. Biophys. Acta 1813, 878-888 (2011)

47. Chen, F. et al. Measuring IL-6 and sIL-6R in serum from patients treated with tocilizumab and/or siltuximab following CAR T cell therapy. J. Immunol. Methods 434, 1-8 (2016)

48. Singh, J. A., Beg, S. \& Lopez-Olivo, M. A. Tocilizumab for rheumatoid arthritis. Cochrane Database of Syst. Rev. CD008331 (2010)

49. Deisseroth, A. et al. FDA approval: siltuximab for the treatment of patients with multicentric Castleman disease. Clin. Cancer Res. 21, 950-954 (2015).

50. Bonifant, C. L., Jackson, H. J., Brentjens, R. J. \& Curran, K. J. Toxicity and management in CAR T-cell therapy. Mol. Ther. Oncolyt. 3, 16011 (2016).

51. Mihara, M. et al. Tocilizumab inhibits signal transduction mediated by both $\mathrm{mIL}-6 \mathrm{R}$ and sIL-6R, but not by the receptors of other members of IL- 6 cytokine family. Int. Immunopharmacol. $\mathbf{5}$, 1731-1740 (2005).

52. Zaki, M. H., Nemeth, J. A. \& Trikha, M. CNTO 328, a monoclonal antibody to IL-6, inhibits human tumorinduced cachexia in nude mice. Int. J. Cancer. 111, 592-595 (2004).

53. Nishimoto, N. et al. Mechanisms and pathologic significances in increase in serum interleukin-6 (IL-6) and soluble IL- 6 receptor after administration of an anti-IL-6 receptor antibody, tocilizumab, in patients with rheumatoid arthritis and Castleman disease. Blood 112, 3959-3964 (2008).

54. Paliogianni, F., Ahuja, S. S., Balow, J. P., Balow, J. E. \& Boumpas, D. T. Novel mechanism for inhibition of human T cells by glucocorticoids. Glucocorticoids inhibit signal transduction through IL-2 receptor. J. Immunol. 151, 4081-4089 (1993)

55. Lanza, L. et al. Prednisone increases apoptosis in in vitro activated human peripheral blood $\mathrm{T}$ lymphocytes. Clin. Exp. Immunol. 103, 482-490 (1996).

56. Franchimont, D. et al. Effects of dexamethasone on the profile of cytokine secretion in human whole blood cell cultures. Regul. Pept. 73, 59-65 (1998).

57. Ozdemir, E. et al. Cytomegalovirus reactivation following allogeneic stem cell transplantation is associated with the presence of dysfunctional antigenspecific CD8 ${ }^{+}$T cells. Blood 100, 3690-3697 (2002)

58. Schultz, D. R. \& Arnold, P. I. Properties of four acute phase proteins: C-reactive protein, serum amyloid $A$ protein, $\alpha_{1}$-acid glycoprotein, and fibrinogen. Semin Arthritis Rheum. 20, 129-147 (1990).

59. Pepys, M. B. \& Hirschfield, G. M. C-Reactive protein: critical update. J. Clin. Invest. 111, 1805-1812 (2003).

60. Schmidt-Arras, D. \& Rose-John, S. IL-6 pathway in the liver: from physiopathology to therapy. J. Hepatol. 64 1403-1415 (2016)

61. Schuster, S. J. et al. Sustained remissions following chimeric antigen receptor modified T cells directed against CD19 (CTL019) in patients with relapsed or refractory CD 19+ lymphomas. Blood 126, 183-183 (2015).

62. Santomasso, B. et al. Biomarkers associated with neurotoxicity in adult patients with relapsed or refractory B-ALL (R/R B-ALL) treated with CD19 CAR T cells [abstract]. J. Clin. Oncol. 35, (15 Suppl.), 3019 (2017).

63. Turtle, C. J. et al. Cytokine release syndrome (CRS) and neurotoxicity (NT) after CD19-specific chimeric antigen receptor- (CAR-) modified T cells [abstract]. J. Clin. Oncol. 35, (15 Suppl.), 3020 (2017).

64. Johnson, L. A. \& June, C. H. Driving gene-engineered $\mathrm{T}$ cell immunotherapy of cancer. Cell Res. 27, 38-58 (2017).

65. Sutter, R., Semmlack, S. \& Kaplan, P. W. Nonconvulsive status epilepticus in adults - insights into the invisible. Nat. Rev. Neurol. 12, 281-293 (2016).

66. Walker, M. et al Nonconvulsive status epilepticus: Epilepsy Research Foundation workshop reports. Epileptic Disord. 7, 253-296 (2005).

67. Hovinga, C. A. Levetiracetam: a novel antiepileptic drug. Pharmacotherapy 21, 1375-1388 (2001)

68. Guenther, S. et al. Chronic valproate or levetiracetam treatment does not influence cytokine levels in humans. Seizure 23, 666-669 (2014). 
69. Reuters. Juno ends development of high-profile leukemia drug after deaths. Reuters http://www.reuters.com/article/us-juno-leukemiaidUSKBN16850Q (2017)

70. Harris, J Kite reports cerebral edema death in ZUMA-1 CAR T-cell trial. OncLive http://www.onclive. com/web-exclusives/kite-reports-cerebral-edemadeath-in-zuma 1-car-tcell-trial (2017).

71. Henter, J. I. et al. HLH-2004: diagnostic and therapeutic guidelines for hemophagocytic Iymphohistiocytosis. Pediatr. Blood Cancer 48 124-131 (2007).

72. Ramos-Casals, M., Brito-Zeron, P., LopezGuillermo, A., Khamashta, M. A. \& Bosch, X. Adult haemophagocytic syndrome. Lancet 383. 1503-1516 (2014)

73. Jordan, M. B., Hildeman, D., Kappler, J. \& Marrack, P. An animal model of hemophagocytic lymphohistiocytosis (HLH): CD8 ${ }^{+} \mathrm{T}$ cells and interferon gamma are essential for the disorder. Blood 104 735-743 (2004)

74. Jordan, M. B., Allen, C. E., Weitzman, S. Filipovich, A. H. \& McClain, K. L. How I treat hemophagocytic lymphohistiocytosis. Blood 118, 4041-4052 (2011).

75. Tamamyan, G. N. et al. Malignancy-associated hemophagocytic lymphohistiocytosis in adults: Relation to hemophagocytosis, characteristics, and outcomes. Cancer 122, 2857-2866 (2016).

76. Daver, N. \& Kantarjian, H. Malignancy-associated haemophagocytic lymphohistiocytosis in adults. Lancet Oncol. 18, 169-171 (2017).

77. Schram, A. M. \& Berliner, N. How I treat hemophagocytic lymphohistiocytosis in the adult patient. Blood 125, 2908-2914 (2015).

78. Jordan, M. et al. A novel targeted approach to the treatment of hemophagocytic lymphohistiocytosis (HLH) with an anti-interferon gamma (IFN $\gamma$ ) monoclonal antibody (mAb), Nl-0501: first results from a pilot phase 2 study in children with primary HLH [abstract]. Blood 126, LBA-3 (2015).

79. Zhou, X. \& Brenner, M. K. Improving the safety of T-Cell therapies using an inducible caspase-9 gene. Exp. Hematol. 44, 1013-1019 (2016).

80. Jackson, H. J., Rafiq, S. \& Brentjens, R. J. Driving CAR T-cells forward. Nat. Rev. Clin. Oncol. 13, 370-383 (2016).

81. Di Stasi, A. et al. Inducible apoptosis as a safety switch for adoptive cell therapy. N. Engl. J. Med. 365, 1673-1683 (2011).

82. Serafini, $M$ et al. Characterization of CD20-transduced T lymphocytes as an alternative suicide gene therapy approach for the treatment of graft-versus-host disease. Hum. Gene Ther. 15, 63-76 (2004).

83. Wang, X. et al. A transgene-encoded cell surface polypeptide for selection. in vivo tracking, and ablation of engineered cells. Blood 118, 1255-1263 (2011)

84. Philip, B. et al. A highly compact epitope-based marker/suicide gene for easier and safer T-cell therapy. Blood 124, 1277-1287 (2014).
85. Thomis, D. C. et al. A Fas-based suicide switch in human T cells for the treatment of graft-versus-host disease. Blood 97, 1249-1257 (2001).

86. Sakemura, R. et al. A Tet-on inducible system for controlling CD19-chimeric antigen receptor expression upon drug administration. Cancer Immunol. Res. 4 , 658-668 (2016)

87. Dai, H., Wang, Y., Lu, X. \& Han, W. Chimeric Antigen receptors modified T-cells for cancer therapy. J. Natl Cancer Inst. 108, djv439 (2016).

88. Morgan, R. A. et al. Case report of a serious adverse event following the administration of T cells transduced with a chimeric antigen receptor recognizing ERBB2. Mol. Ther. 18, 843-851 (2010).

89. Ahmed, N. et al. Human epidermal growth factor receptor 2 (HER2)-specific chimeric antigen receptor modified T cells for the immunotherapy of HER2-positive sarcoma. J. Clin. Oncol. 33 , 1688-1696 (2015)

90. Parkhurst, M. R. et al. T cells targeting carcinoembryonic antigen can mediate regression of metastatic colorectal cancer but induce severe transient colitis. Mol. Ther. 19, 620-626 (2011).

91. Lamers, C. H. et al. Treatment of metastatic renal cell carcinoma with CAIX CAR-engineered T cells: clinical evaluation and management of on-target toxicity. Mol. Ther. 21, 904-912 (2013).

92. Lamers, C. H. et al. Treatment of metastatic renal cell carcinoma with autologous T-lymphocytes genetically retargeted against carbonic anhydrase IX: first clinical experience. J. Clin. Oncol. 24, e20-e22 (2006).

93. Maus, M. V. et al. T cells expressing chimeric antigen receptors can cause anaphylaxis in humans. Cancer Immunol. Res. 1, 26-31 (2013).

94. Brentjens, R., Yeh, R., Bernal, Y., Riviere, I. \& Sadelain, M. Treatment of chronic lymphocytic leukemia with genetically targeted autologous T cells: case report of an unforeseen adverse event in a phase I clinical trial. Mol. Ther. 18, 666-668 (2010)

95. Chong, E. A. et al. Chimeric antigen receptor modified T cells directed against CD19 (CTL019) in patients with poor prognosis, relapsed or refractory CD19 follicular lymphoma: prolonged remissions relative to antecedent therapy [abstract]. Blood 128, 1100 (2016)

96. Locke, $F$ L et al A phase 2 multicenter trial of KTE-C19 (anti-CD19 CAR T Cells) in patients with chemorefractory primary mediastinal B-cell lymphoma (PMBCL) and transformed follicular lymphoma (TFL) interim results from ZUMA-1 [abstract]. Blood 128, 998 (2016)

97. Russell, J. A. et al. Vasopressin versus norepinephrine infusion in patients with septic shock. N. Engl. J. Med. 358, 877-887 (2008).

98. Frisen, L. Swelling of the optic nerve head: a staging scheme. J. Neurol. Neurosurg. Psychiatry 45, 13-18 (1982)
Acknowledgements

The work of S.S.N. is supported by The University of Texas MD Anderson Cancer Center Support Grant (P30 CA016672) from the US Department of Health $\&$ Human Services, National Institutes of Health, and by generous philanthropic contributions to the University of Texas MD Anderson Moon Shots Program.

Author contributions

S.S.N. and S.T. contributed equally to this article, and wrote the manuscript. S.S.N., S.T., N.J., N.D., A.M.G., and S.A. contributed to researching data for article. All authors contributed to discussions of content, to the development of the proposed guidelines, and to review/editing of the manuscript before submission.

\section{Competing interests statement}

S.S.N. has received research support from Bristol-Myers Squibb, Celgene, Cellectis, Kite Pharma, Merck, and Poseida Therapeutics. S.S.N. has also served as a consultant and/or Scientific Advisory Board member for Celgene, Kite Pharma, Merck, and Novartis. S.T. served as a Scientific Advisory Board member for Kite Pharma. F.L.L. has served as a Scientific Advisory Board member for Kite Pharma, and as a Consultant to Cellular Biomedicine Group. K.V.K. has served as a scientific advisor to and has received research funding from Juno Therapeutics and Kite Pharma. Y.L. has received research funding from Janssen. N.J. has received research support from Abbvie, ADC Therapeutics, Bristol-Myers Squibb, Celgene, Genentech, Incyte, Pharmacyclics, Pfizer, Seattle Genetics, Servier, and Verastem. N.J. has also served on the advisory board and received honorarium from Adaptive Biotechnologies, ADC Therapeutics, Novartis, Novimmune, Pharmacyclics, Pfizer, Servier, and Verastem. N.D. has received research support from Bristol-Myers Squibb, DaichiSanky, Incyte, Karyopharm, Pfizer, and Sunesis. N.D. has also received served as a consultant for Incyte, Jazz, Karyopharm, Novartis, Otsuka, Pfizer, and Sunesis. J.W. has received research funding and served on the Advisory Boards for Kite Pharma and Novartis. J.F.d.G. has received research support from Astrazeneca, Deciphera Pharmaceuticals, Eli Lilly, EMDSerono, Mundipharma, Novartis, Sanofi-Aventis. J.F.d.G. has also served as a consultant or Advisory Board member for AbbVie, Astrazeneca, Celldex, Deciphera Pharmaceuticals, FivePrime Therapeutics, Foundation Medicine, Genentech, Insys Therapeutics, Kadmon, Merck, Novartis, and Novogen. J.F.d.G. is a stock owner of Gilead and Ziopharm Oncology, and his spouse is employed by Ziopharm Oncology. S.A served as an Advisory Board member for Kite Pharma. K.R. is on the Independent Data Monitoring Committee for Kiadis Pharma. The other authors declare no competing interests.

Publisher's note

Springer Nature remains neutral with regard to jurisdictional claims in published maps and institutional affiliations.

SUPPLEMENTARY INFORMATION See online article: $\mathrm{S} 1$ (table) |S2 (table) ALL LINKS ARE ACTIVE IN THE ONLINE PDF 